\title{
From molecular clusters to nanoparticles: second-generation ion-mediated nucleation model
}

\author{
F. Yu \\ Atmospheric Sciences Research Center, State University of New York, 251 Fuller Road, Albany, New York, 12203, USA \\ Received: 16 January 2006 - Published in Atmos. Chem. Phys. Discuss.: 13 April 2006 \\ Revised: 09 October 2006 - Accepted: 31 October 2006 - Published: 15 November 2006
}

\begin{abstract}
Ions, which are generated in the atmosphere by galactic cosmic rays and other ionization sources, may play an important role in the formation of atmospheric aerosols. In the paper, a new second-generation ion-mediated nucleation (IMN) model is presented. The new model explicitly treats the evaporation of neutral and charged clusters and it describes the evolution of the size spectra and composition of both charged and neutral clusters/particles ranging from small clusters of few molecules to large particles of several micrometers in diameter. Schemes used to calculate the evaporation coefficients for small neutral and charged clusters are consistent with the experimental data within the uncertainty range. The present IMN model, which is size-, composition-, and type-resolved, is a powerful tool for investigating the dominant mechanisms and key parameters controlling the formation and subsequent growth of nanoparticles in the atmosphere. This model can be used to analyze simultaneous measurements of the ion-mobility spectra and particle size distributions, which became available only recently. General features of the spectra for ions smaller than the critical size, size-dependent fractions of charged nanoparticles, and asymmetrical charging of freshly nucleated particles predicted by the new IMN model are consistent with recent measurements. Results obtained using the second generation IMN model, in which the most recent thermodynamic data for neutral and charged $\mathrm{H}_{2} \mathrm{SO}_{4}-\mathrm{H}_{2} \mathrm{O}$ clusters were used, suggest that ion-mediated nucleation of $\mathrm{H}_{2} \mathrm{SO}_{4}$ $\mathrm{H}_{2} \mathrm{O}$ can lead to a significant production of new particles in the lower atmosphere (including the boundary layer) under favorable conditions. It has been shown that freshly nucleated particles of few nanometers in size can grow by the condensation of low volatile organic compounds to the size of cloud condensation nuclei. In such cases, the chemical composition of nucleated particles larger than $\sim 10 \mathrm{~nm}$ is dominated by organics.
\end{abstract}

Correspondence to: $\mathrm{F} . \mathrm{Yu}$

(yfq@asrc.cestm.albany.edu)

\section{Introduction}

Atmospheric aerosols from both natural and anthropogenic sources indirectly impact the Earth climate through the effect on the cloud formation and properties, and precipitation (e.g., Twomey, 1977; Charlson et al., 1992). Indirect radiative forcing is poorly constrained in the existing climate models and this represents the single greatest uncertainty in assessing the climate change (Penner et al., 2001). Another important issue is that the particles in the atmosphere can cause visibility degradation and adverse health effects. Climatic, health and environmental impacts of atmospheric particles depend strongly on the size spectra and compositions of aerosols in the Earth atmosphere. These properties are governed by a number of microphysical processes (e.g. nucleation, condensational growth and coagulation) taking place simultaneously. New particle formation has been observed in various locations in the lower troposphere (e.g., Kulmala et al., 2004a). Some observations have indicated that significant numbers of newly formed particles can grow to the size of the cloud condensation nuclei $(\mathrm{CCN})$ within a day under favorable conditions (Kulmala, 2003; Stanier et al., 2004; Zhang et al., 2004a; Wehner et al., 2005; Laaksonen et al., 2005; Stolzenburg et al., 2005). A clear and insightful understanding of the mechanisms responsible for the formation of the atmospheric particles is critically important for quantitative assessment of the climate-related, health and environmental impacts of atmospheric aerosols.

Binary homogeneous nucleation (BHN) of sulfuric acid and water has been considered for a long time as a dominant mechanism of the new particle formation. However, it has been recently found that BHN theory can't explain the observed nucleation events in the lower troposphere (e.g, Weber et al, 1996; Clarke et al., 1998). Ternary homogeneous nucleation (THN) theory, which involves $\mathrm{H}_{2} \mathrm{SO}_{4}, \mathrm{H}_{2} \mathrm{O}$ and $\mathrm{NH}_{3}$ (e.g., Coffman and Hegg, 1995; Korhonen et al., 1999; Napari et al., 2002), and ion-mediated nucleation $\left(\mathrm{H}_{2} \mathrm{SO}_{4}\right.$ $\mathrm{H}_{2} \mathrm{O}-\mathrm{Ion}$ ) (Yu and Turco, 2000, 2001) have been proposed as

Published by Copernicus GmbH on behalf of the European Geosciences Union. 
alternative mechanisms of the particle formation. The actual role of $\mathrm{NH}_{3}$ in the atmospheric nucleation remains unclear because the difference between experimental results and predictions of THN is excessively large (Yu, 2006a). Preliminary simulations performed using a kinetically consistent THN model constrained using the experimental data indicate that the contribution of THN to the formation of new particles in the boundary layer is negligible (Yu, 2006a). Other recently proposed nucleation mechanisms include nucleation of iodine species (O'Dowd et al., 2002) and organics compounds (Zhang et al., 2004b). It may be possible that all the above nucleation mechanisms contribute to the formation of new particles in the atmosphere and that the atmospheric nucleation under different conditions may be dominated by different nucleation mechanisms. The present paper is focused on the ion-mediated nucleation.

Yu and Turco $(1997,1998,2000,2001)$ developed a novel approach to study the nucleation on ions. The new approach is based on a kinetic model that explicitly solves the complex interactions among ions, neutral and charged clusters of various sizes, vapor molecules, and pre-existing particles. Compared to homogeneous nucleation involving neutral clusters, the nucleation on ions is favored because: (1) The small charged clusters are much more stable thermodynamically; (2) Growth rate of small ion clusters is enhanced by the dipole-charge interaction between charged clusters and strongly dipolar precursor molecules and, thus, ionic clusters grow faster than neutrals. Evolution of the size distributions of both charged and neutral clusters in the presence of ionization, neutralization, coagulation, and scavenging leads to a net flux of clusters crossing the critical size (i.e., nucleation). This mechanism is referred to as the ionmediated nucleation (IMN) (Yu and Turco, 2000). In recent years there is a continuously growing interest to the nucleation of $\mathrm{H}_{2} \mathrm{SO}_{4}-\mathrm{H}_{2} \mathrm{O}$ on ions ( $\mathrm{Yu}, 2002$; Carslaw et al., 2002; Eichkorn et al., 2002; Laakso et al., 2003; Lee et al., 2003; Harrison and Carslaw, 2003; Lovejoy et al., 2004; Wilhelm et al., 2004; Sorokin et al., 2006). The mobility distribution of charged clusters/particles measured with the ion mobility spectrometers (Tammet, 2006) provide useful information about the possible involvement of ions in the atmospheric nucleation (Hõrrak et al., 1998; Tamm et al., 2001; Mäkelä et al., 2003; Laakso et al., 2004; Vana et al., 2006; Iida et al., 2005). In the earlier version of the IMN model (Yu and Turco, 1997, 2001), the compositions of neutral and charged clusters were assumed to be the same and the evaporation of small clusters was accounted for using a simple adjustment to the condensation accommodation coefficients due to the lack of thermodynamic data for the small clusters. This quite rough approximation likely leads to significant uncertainties in predicted nucleation rates in the atmosphere. Recently, Lovejoy et al. (2004) developed a kinetic ion nucleation model, which explicitly treats the evaporation of small neutral and negatively charged clusters. The thermodynamic data used in their model were obtained via a combination of derivations from measurements of small ion clusters, $a b$ initio calculations, thermodynamic cycle, and some approximations (adjustment of Gibbs free energy for neutral clusters calculated based on liquid droplet model, interpolation, etc.). Some uncertainties in the thermodynamic data used in the model of Lovejoy et al. (2004) are expected. Lovejoy et al. (2004) stated that the nucleation of $\mathrm{H}_{2} \mathrm{SO}_{4}$ (and $\mathrm{H}_{2} \mathrm{O}$ ) on negative ions does not generally explain the observed nucleation events in the boundary layer. Recent observations of the overcharge of 3-5 nm particles show that ions are involved in the nucleation in the boundary layer (Laakso et al., 2004; Vana et al., 2006; Iiad et al., 2005). Sorokin et al. (2006) reported laboratory investigation of positive and negative $\mathrm{H}_{2} \mathrm{SO}_{4}-\mathrm{H}_{2} \mathrm{O}$ cluster ions and they showed that small positive ions are markedly enriched in $\mathrm{H}_{2} \mathrm{O}$ and negative ions are enriched in $\mathrm{H}_{2} \mathrm{SO}_{4}$ molecules. Sorokin et al. (2006) also developed an ion-cluster-aerosol kinetic model which uses the thermochemistry data reported in Froyd and Lovejoy (2003a, b) and empirical correction terms suggested in Lovejoy et al. (2004). Sorokin et al. (2006) compared their model predictions with laboratory measurements but didn't discuss what their model will predict under ambient atmospheric conditions.

In the last few years, we have made substantial progress in understanding the molecular nature and thermodynamics of small charged clusters (Nadykto et al. 2003, 2006; Nadykto and Yu, 2003; 2004; Yu, 2005a) and derived a modified Kelvin-Thomson (MKT) equation that accurately takes into account the dipole-charge interactions (Yu, 2005a). The thermodynamic data for small ion clusters derived from recent MKT equation are in much better agreement with experiments than those obtained using the classical KelvinThomson equation (Yu, 2005a). We have also developed a scheme to calculate the evaporation of $\mathrm{H}_{2} \mathrm{SO}_{4}$ molecules from neutral $\mathrm{H}_{2} \mathrm{SO}_{4}-\mathrm{H}_{2} \mathrm{O}$ clusters ( $\mathrm{Yu}, 2005 \mathrm{~b}, 2006 \mathrm{~b}$ ). This scheme, in which the most recent thermodynamic data for $\mathrm{H}_{2} \mathrm{SO}_{4}-\mathrm{H}_{2} \mathrm{O}$ binary system are used, explicitly includes the hydration effect and it predicts $\mathrm{H}_{2} \mathrm{SO}_{4}-\mathrm{H}_{2} \mathrm{O}$ homogeneous nucleation rates within the uncertainty range of the experimental data (Yu, 2005b, 2006b). In this paper we present a second-generation model of IMN, which treats the evaporation of neutral/charged clusters explicitly using recently developed schemes. The model also takes into account the difference in the composition and thermodynamics of small positive and negative ions, and can be used to study the effect of the sign preference on the nucleation in the Earth atmosphere. In addition to a rigorous treatment of sulfuric acid-water clusters, the condensation of organic species on freshly nucleated particles has been included in the present model. Our model explicitly simulates the evolution of the size spectra and composition of neutral, positively charged and negatively charged clusters. The model has a capability of analyzing the recent simultaneous ion mobility distribution and particle charge state measurements. 


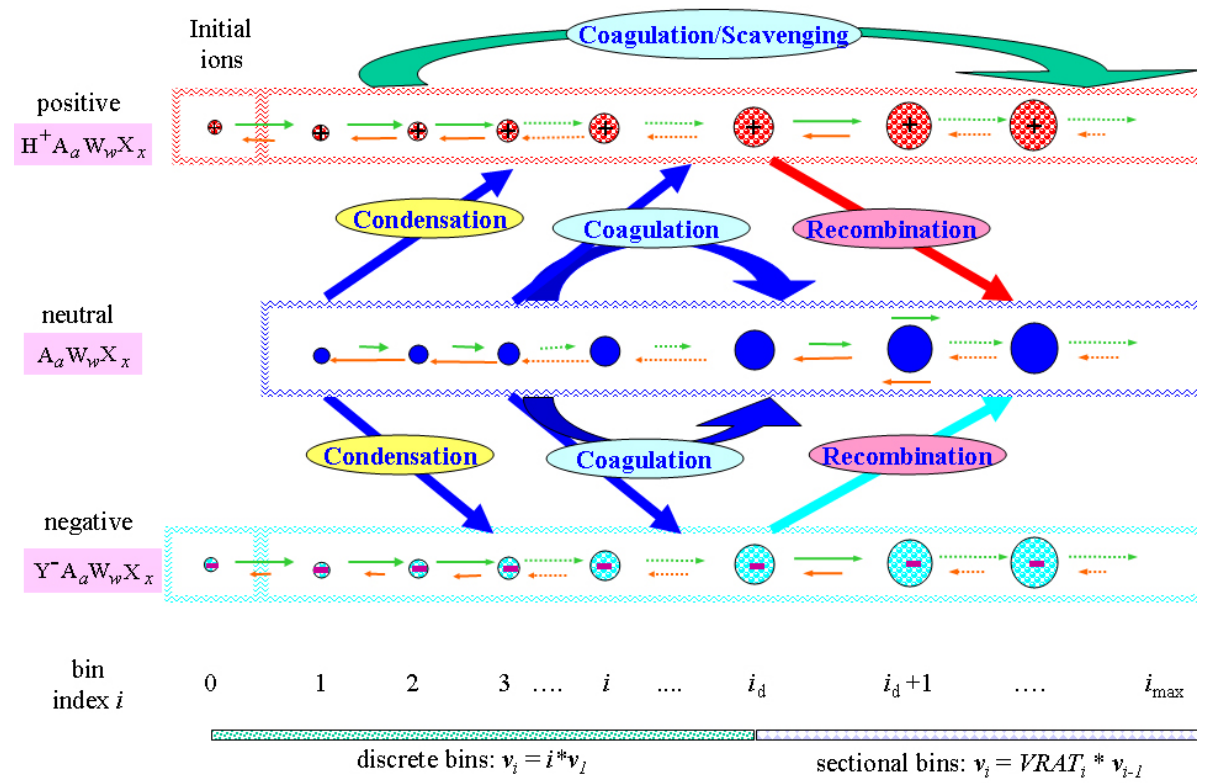

Fig. 1. Schematical illustration of kinetic processes controlling the evolution of positively charged $\left(\mathrm{H}^{+} \mathrm{A}_{a} \mathrm{~W}_{w} \mathrm{X}_{x}\right)$, neutral $\left(\mathrm{A}_{a} \mathrm{~W}_{w} \mathrm{X}_{x}\right)$, and negatively charged $\left(\mathrm{Y}^{-} \mathrm{A}_{a} \mathrm{~W}_{w} \mathrm{X}_{x}\right)$ clusters/particles that are explicitly simulated in the size-, composition-, and type-resolved IMN model (see text for details). The model uses the discrete-sectional bin structure to represent the sizes of clusters/particles.

\section{Ion mediated nucleation (IMN) model}

\subsection{The kinetic nucleation processes}

New particle formation is a dynamic process involving various interactions among precursor gas molecules, small clusters, and pre-existing particles. Figure 1 illustrates schematically the evolution of positively charged $\left(\mathrm{H}^{+} \mathrm{A}_{a} \mathrm{~W}_{w} \mathrm{X}_{x}\right)$, neu$\operatorname{tral}\left(\mathrm{A}_{a} \mathrm{~W}_{w} \mathrm{X}_{x}\right)$, and negatively charged $\left(\mathrm{Y}^{-} \mathrm{A}_{a} \mathrm{~W}_{w} \mathrm{X}_{x}\right)$ clusters/droplets that is explicitly simulated in the new kinetic IMN model. Here A, $\mathrm{W}$, and $\mathrm{X}$ represent the sulfuric acid $\left(\mathrm{H}_{2} \mathrm{SO}_{4}\right)$, water $\left(\mathrm{H}_{2} \mathrm{O}\right)$, and other possible species (for example, organics, $\mathrm{NH}_{3}$, etc.), respectively, while a, w, and $\mathrm{x}$ refer to the number of $\mathrm{A}, \mathrm{W}$, and $\mathrm{X}$ molecules in the clusters/droplets, respectively. $\mathrm{Y}^{-}$is an abbreviation for the negative core ion. The initial positive ions are assumed to be $\mathrm{H}^{+} \mathrm{W}_{w}$. The initial ions are generated by galactic cosmic rays (GCRs) and by other sources (radioactive emanations, lightning, corona discharge, combustion, etc.). Measurements of nature negative ion mass spectrum (Eisele and Tanner, 1990) indicate the presence of $\mathrm{NO}_{3}^{-}, \mathrm{HSO}_{4}^{-}, \mathrm{SO}_{4} \mathrm{NO}_{2}^{-}$, $\mathrm{SO}_{4} \mathrm{NO}_{3}^{-}$, malonate ion, etc. The negative ions are dominated by $\mathrm{NO}_{3}^{-}$core ions at low sulfuric acid gas concentration but are generally dominated by $\mathrm{HSO}_{4}^{-}$core ions when sulfuric acid gas concentration is high. The modified Kelvin Thomson equation used to calculate the charge effect considers the effect of the size of core ions but is not able to take into account the effect of core ion composition (see Sect. 2.3). In this study, we assume that the core of negative ions to be $\mathrm{NO}_{3}^{-}$. However, during the nucleation events when $\left[\mathrm{H}_{2} \mathrm{SO}_{4}(\mathrm{~g})\right]$ is relatively high, the negative ions may be dominated by $\mathrm{HSO}_{4}^{-}$core ions. The uncertainty in charge effect associated with core ion sizes $\left(\mathrm{NO}_{3}^{-}\right.$versus $\left.\mathrm{HSO}_{4}^{-}\right)$for small ions is smaller than the uncertainty in experimental data and is likely to be small for larger cluster ions (see Sect. 2.4).

Compared to the neutral clusters, charged clusters have higher growth rates and lower evaporation rates as a result of interaction between ions and polar or polarizable host vapor molecules (Yu and Turco, 1997, 2001; Nadykto and Yu, 2004; Yu, 2005a). Thus, charged clusters have a great growth advantage over the neutral ones that is very important for the nucleation. Size to which a charged cluster can grow depends on the cluster growth rate that is largely determined by concentrations of precursor gases, evaporation coefficient, which is a function of the ambient temperature, radius and composition of clusters, the charge effect, and lifetime due to the recombination, which is governed by concentrations and size spectra of ions of the opposite sign. Recombination of oppositely charged clusters is a major source of large neutral clusters under typical conditions in the lower atmosphere. Neutral clusters resulted from the recombination may shrink due to evaporation if they are smaller than the critical size; however they may grow to larger size and finally become "nucleated", if they are bigger than the critical size. In 

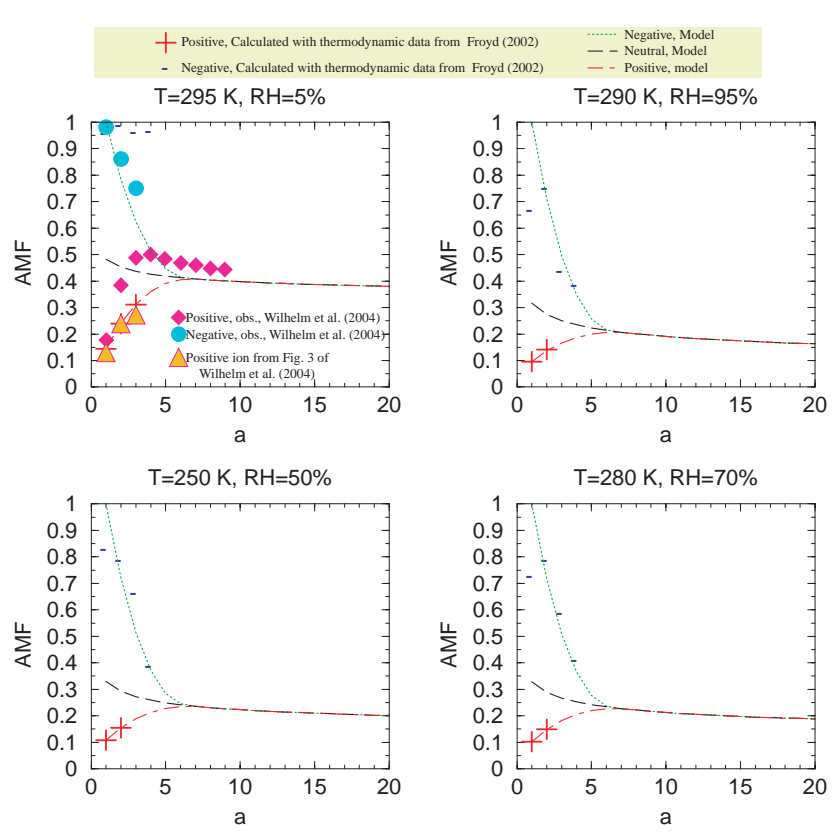

Fig. 2. Sulfuric acid mole fractions $\mathrm{AMF}^{+}, \mathrm{AMF}^{-}, \mathrm{AMF}^{0}$ as functions of cluster sizes under 4 different atmospheric conditions (see text for details).

addition to the condensation of neutral monomers, both neutral and charged clusters can grow by collecting smaller clusters and they may also be scavenged by larger pre-existing particles. The neutral particles can become charged by collecting small ions (ion attachment), while charged particles may be neutralized by attachment of ions or clusters of the opposite sign.

In the present study, kinetic processes controlling the evolution of neutral, positively charged, and negatively charged clusters/particles were explicitly simulated using the new size-, composition-, and type- resolved IMN model, which has been built based on the earlier versions of aerosol microphysics model originally developed by Turco and colleagues (Turco et al., 1979; Hamill et al., 1982; Toon et al., 1988; Jacobson et al., 1994; Jacobson and Turco, 1995; Yu and Turco, 1998, 2001).

The current model uses the discrete-sectional bin structure to represent the size spectra of molecular clusters/particles. The bin sizes represent the dry sizes of clusters/particles and corresponding wet sizes are calculated based on the equilibrium of clusters/particles with the water vapor (Jacobson and Turco, 1995). For small clusters, the dry volume of $i$ th bin $v_{i}=i^{*} v_{1}$, where $i$ is the bin index and $v_{1}$ is the volume of first bin (in this study $v_{1}$ is the volume of $\mathrm{H}_{2} \mathrm{SO}_{4}$ molecule). When $i>i_{d}$ ( $i_{d}$ is set to be 30 in this study), $v_{i}=\operatorname{VRAT}_{i}$ * $v_{i-1}$, where $\operatorname{VRAT}_{i}$ is the volume ratio of $i^{\text {th }}$ bin to $(i-1)^{\text {th }}$ bin. VRAT $i$ depends on $i$ and increases gradually from $\left(i_{d}\right.$ $+1) / i_{d}$ to a maximum value of $\mathrm{VRAT}_{\max }(1.5$ in this study) as $i\left(>i_{d}\right)$ increases.

\subsection{Average compositions of clusters}

$\mathrm{H}_{2} \mathrm{SO}_{4}$ (A) and $\mathrm{H}_{2} \mathrm{O}$ (W) are known to play an important role in the particle formation in the atmosphere (Fiedler et al., 2005; Kulmala et al., 2006). In a wide range of the atmospheric conditions, the specie dominating the growth of small clusters is $\mathrm{H}_{2} \mathrm{SO}_{4}$; however, organic species may dominate the growth rate of nucleated nanoparticles (Kulmala et al., 2004b). The contribution of $\mathrm{H}_{2} \mathrm{O}$ to the nucleation relates to the hydration of $\mathrm{H}_{2} \mathrm{SO}_{4}$ clusters (or, in the other words, modification of the composition of binary $\mathrm{H}_{2} \mathrm{SO}_{4}$ $\mathrm{H}_{2} \mathrm{O}$ clusters) that reduces the $\mathrm{H}_{2} \mathrm{SO}_{4}$ vapor pressure over the binary $\mathrm{H}_{2} \mathrm{SO}_{4}-\mathrm{H}_{2} \mathrm{O}$ clusters and, hence, diminishes the evaporation of $\mathrm{H}_{2} \mathrm{SO}_{4}$ from the clusters. $\mathrm{NH}_{3}$ (and/or some organic compounds) may also be involved in the nucleation process because they may stabilize the cluster and reduce the evaporation coefficient of $\mathrm{H}_{2} \mathrm{SO}_{4}$ from clusters due to the change in the cluster composition. Recent analysis of experimental study on ternary nucleation indicates that $\mathrm{NH}_{3}$ is unlikely able to stabilize the small $\mathrm{H}_{2} \mathrm{SO}_{4}-\mathrm{H}_{2} \mathrm{O}$ molecular clusters, though the presence of $\mathrm{NH}_{3}$ may contribute to a stability of larger clusters/droplets (Yu, 2006a). The possible involvement of $\mathrm{NH}_{3}$ and organics in the formation of precritical clusters, which remains to be established, is out of the scope of the present study.

In the case of the nucleation in systems involving $\mathrm{H}_{2} \mathrm{SO}_{4}(\mathrm{~A}), \mathrm{H}_{2} \mathrm{O}$ (W) and ions, which are of the primary interest, the number concentration of water vapor molecules is much larger than that of $\mathrm{H}_{2} \mathrm{SO}_{4}$ vapor and ions. Neutral and charged sulfuric acid clusters of various sizes (including monomers) can be considered to be in instantaneous equilibrium with the water vapor, and their composition (i.e., number of $\mathrm{H}_{2} \mathrm{O}$ molecules $w$ in a cluster containing $a \mathrm{H}_{2} \mathrm{SO}_{4}$ molecules) can be approximated using the average composition. In such a case, the nucleation process is controlled by the growth/evaporation of clusters through the uptake/evaporation of $\mathrm{H}_{2} \mathrm{SO}_{4}$ molecules and coagulation among clusters. Assumptions about the instantaneous equilibrium of $\mathrm{H}_{2} \mathrm{SO}_{4}-\mathrm{H}_{2} \mathrm{O}$ clusters with the water vapor and the dominating role of $\mathrm{H}_{2} \mathrm{SO}_{4}$ in nucleation are basic assumptions in all the recently developed kinetic $\mathrm{H}_{2} \mathrm{SO}_{4}-\mathrm{H}_{2} \mathrm{O}$ nucleation models (Yu and Turco, 1997, 1998, 2001; Yu, 2005b, 2006b; Lovejoy et al., 2004).

In the new IMN model, the average equilibrium compositions of neutral clusters are calculated using the liquid droplet approximation (Kelvin Equation). Measurements for both positive $\left(\mathrm{H}^{+} \mathrm{A}_{a} \mathrm{~W}_{w}\right)$ and negative $\left(\mathrm{Y}^{-} \mathrm{A}_{a} \mathrm{~W}_{w}\right)$ ionic clusters indicate that their composition is quite different from that of the corresponding neutral clusters, when the clusters are small $(a<\sim 5)$. However, the deviation disappears, when clusters become large $(a>\sim 5)$ (Froyd, 2002; Wilhelm et al., 2004). Small $\mathrm{Y}^{-} \mathrm{A}_{a} \mathrm{~W}_{w}$ ions have a strong preference for A-ligands (i.e., higher A-ligand mole fraction), while small $\mathrm{H}^{+} \mathrm{A}_{a} \mathrm{~W}_{w}$ ions have a strong preference for $\mathrm{W}-$ ligands (i.e., lower A-ligand mole fraction). In the new IMN 
model, we parameterized the average A-ligand mole fraction $\left(\mathrm{AMF}=\frac{a}{a+w}\right)$ for the positively charged $\left(\mathrm{AMF}^{+}\right)$and negatively charged $\left(\mathrm{AMF}^{-}\right)$clusters as

$$
\begin{aligned}
\operatorname{AMF}^{+,-}(a) & =\operatorname{AMF}^{0}\left(a_{0}\right)+\left[\operatorname{AMF}^{+,-}(1)-\operatorname{AMF}^{0}\left(a_{0}\right)\right] \\
& \times\left(\frac{a_{0}-a}{a_{0}-1}\right)^{2.5}, a<a_{0}
\end{aligned}
$$

$\operatorname{AMF}^{+}(a)=\operatorname{AMF}^{-}(a)=\operatorname{AMF}^{0}(a), a \geq a_{0}$

where $\operatorname{AMF}^{0}(a)$ is the A-ligand mole fraction for neutral clusters containing $a \mathrm{H}_{2} \mathrm{SO}_{4}$ molecules. In the above parameterizations, it was assumed that charged clusters have the same AMF as neutral ones at $a \geq a_{0}$. In this study, we use $a_{0}=7$ and $\mathrm{AMF}^{-}(1)=1 . \mathrm{AMF}^{+}(1)$ is calculated using thermodynamic data from Froyd and Lovejoy (2003a, b).

Figure 2 shows $\mathrm{AMF}^{+}, \mathrm{AMF}^{-}, \mathrm{AMF}^{0}$ as functions of $a$ under 4 different atmospheric conditions. The black dashed lines are $\mathrm{AMF}^{0}$ calculated using the liquid droplet approximation as described in Yu (2005b, 2006b). The dot-dashed and dotted lines are $\mathrm{AMF}^{+}$and $\mathrm{AMF}^{-}$computed using parameterizations described above. The pluses ("+") and minuses ("-") refer to $\mathrm{AMF}^{+}$and $\mathrm{AMF}^{-}$calculated using the step-wise water-ion clustering enthalpy and entropy data from Froyd and Lovejoy (2003a, b). In Fig. 2(a), the data from Wilhelm et al. (2004) are also shown (Negative ions: filled circles; Positive ions: diamonds and triangles). Since we found that the $\mathrm{AMF}^{+}$values shown in two figures (Fig. 6 and Fig. 3) in Wilhelm et al. (2004) are different, both data sets are shown in Fig. 2a. At temperature $(T)$ of $295 \mathrm{~K}$ and relative humidity $(\mathrm{RH})$ of $5 \%$, the $\mathrm{AMF}^{+}$values calculated using Froyd and Lovejoy's thermodynamic data are close to the set of the data derived from ion mass spectra reported in Wilhelm et al. (2004). However, the $\mathrm{AMF}^{-}$calculated using thermodynamic data from Froyd and Lovejoy (2003a, b), which does not show the trend to approach $\mathrm{AMF}^{0}$ as $a$ increases, are quite different from those presented in Wilhelm et al. (2004). At this point, it is hard to determine the reason for the difference and the uncertainty in the measurements. Our parameterization should be considered as an approximation which may contribute to the uncertainty in the predicted nucleation rates. More data are clearly needed to constrain the model and reduce the uncertainty. At high $\mathrm{RH}$, there exists difference between the parameterized hydration of $a=1$ clusters and the calucations based on experimental data. However, the difference shall have little effect on nucleation as the charge effect dominates the thermodynamics when clusters are very small (see Sect. 2.4). Figure 2 shows clearly that both $\mathrm{AMF}^{+}$and $\mathrm{AMF}^{-}$calculated using our own parameterizations are in reasonable agreement with those observed at low RH (Wilhelm et al., 2004) and those calculated using the thermodynamic data from Froyd and Lovejoy (2003a, b) at high RH. At given AMFs, the properties of clusters/droplets (density, size, surface tension, saturation vapor
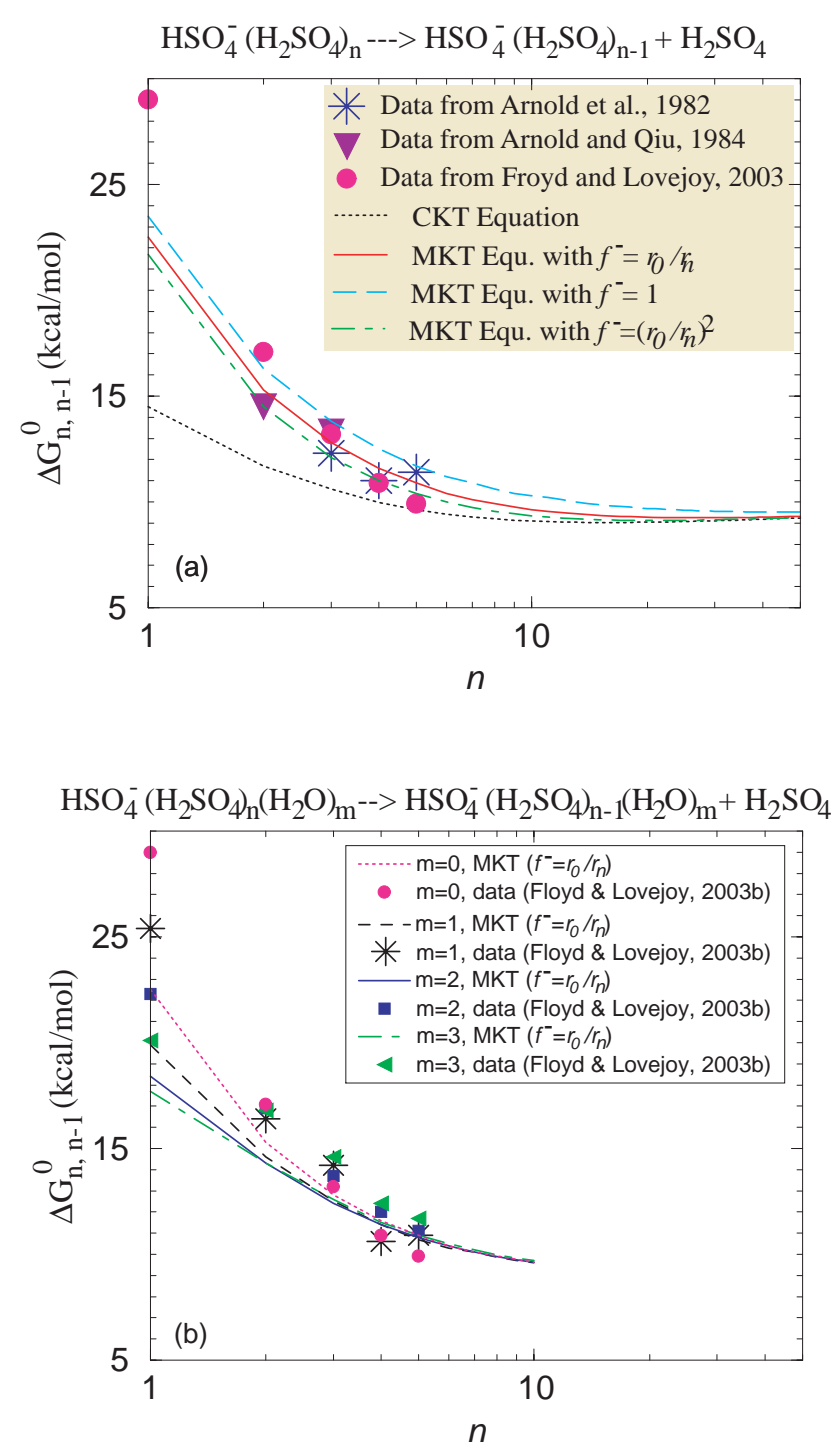

Fig. 3. Step-wise Gibbs free energy changes under the standard condition $\left(\Delta G_{n, n-1}^{0}\right)$ for the evaporation of $\mathrm{H}_{2} \mathrm{SO}_{4}$ from (a) $\mathrm{HSO}_{4}^{-}\left(\mathrm{H}_{2} \mathrm{SO}_{4}\right)_{\mathrm{n}}$ and (b) $\mathrm{HSO}_{4}^{-}\left(\mathrm{H}_{2} \mathrm{SO}_{4}\right)_{\mathrm{n}}\left(\mathrm{H}_{2} \mathrm{O}\right)_{\mathrm{m}}$. The predictions based on traditional CKT equation (Holland and Castleman, 1982) are shown in Fig. 3a only.

pressure, etc.) were decided using the bulk liquid droplet approximation.

\subsection{Differential equations}

The evolution of three different types of clusters (as shown in Fig. 1) is described by the following set of the differential equations 


$$
\begin{aligned}
& \frac{\partial C_{i, Y}^{+}}{\partial t}=\delta_{Y, Y_{\text {nucl }}} g_{i+1, i} \gamma_{i+1}^{+} C_{i+1, Y}^{+}-g_{i, i-1} \gamma_{i}^{+} C_{i, Y}^{+} \\
& +\sum_{j=0}^{i-1} \sum_{k=1}^{i} f_{j, k, i} \beta_{j, k}^{+} C_{j, Y}^{+} N_{k}^{0}+\sum_{j=0}^{i-1} \sum_{k=0}^{i} f_{j, k, i} \eta_{j, k}^{+} C_{j, Y}^{+} N_{k}^{+}+\sum_{j=0}^{i} \sum_{k=1}^{i} f_{j, k, i} \beta_{j, k}^{+} N_{j}^{+} C_{k, Y}^{0}, \quad i \geq 1 \\
& -C_{i, Y}^{+}\left(\sum_{j=1}^{i_{\max }}\left(1-f_{i, j, i}\right) \beta_{i, j}^{+} N_{j}^{0}+\sum_{j=0}^{i_{\max }}\left(1-f_{i, j, i}\right) \eta_{i, j}^{+} N_{j}^{+}+\sum_{j=0}^{i_{\max }} \alpha_{i, j}^{+,-} N_{j}^{-}\right) \\
& \frac{\partial N_{0}^{+}}{\partial t}=Q+\gamma_{1}^{+} N_{1}^{+}-N_{0}^{+}\left(\sum_{j=1}^{i_{\max }} \beta_{i, j}^{+} N_{j}^{0}+\sum_{j=0}^{i_{\max }} \eta_{i, j}^{+} N_{j}^{+}+\sum_{j=0}^{i_{\max }} \alpha_{0, j}^{+,-} N_{j}^{-}\right) \\
& \frac{\partial C_{i, Y}^{-}}{\partial t}=\delta_{Y, Y_{\text {nucl }}} g_{i+1, i} \gamma_{i+1}^{-} C_{i+1, Y}^{-}-g_{i, i-1} \gamma_{i}^{-} C_{i, Y}^{-} \\
& +\sum_{j=0}^{i-1} \sum_{k=1}^{i} f_{j, k, i} \beta_{j, k}^{-} C_{j, Y}^{-} N_{k}^{0}+\sum_{j=0}^{i-1} \sum_{k=0}^{i} f_{j, k, i} \eta_{j, k}^{-} C_{j, Y}^{-} N_{k}^{-}+\sum_{j=0}^{i} \sum_{k=1}^{i} f_{j, k, i} \beta_{j, k}^{-} N_{j}^{-} C_{k, Y}^{0} \quad, \quad i \geq 1 \\
& -C_{i, Y}^{-}\left(\sum_{j=1}^{i_{\max }}\left(1-f_{i, j, i}\right) \beta_{i, j}^{-} N_{j}^{0}+\sum_{j=0}^{i_{\max }}\left(1-f_{i, j, i}\right) \eta_{i, j}^{-} N_{j}^{-}+\sum_{j=0}^{i_{\max }} \alpha_{i, j}^{-,+} N_{j}^{+}\right) \\
& \frac{\partial N_{0}^{-}}{\partial t}=Q+\gamma_{1}^{-} N_{1}^{-}-N_{0}^{-}\left(\sum_{j=1}^{i_{\max }} \beta_{i, j}^{-} N_{j}^{0}+\sum_{j=0}^{i_{\max }} \eta_{i, j}^{-} N_{j}^{-}+\sum_{j=0}^{i_{\max }} \alpha_{0, j}^{-,+} N_{j}^{+}\right) \\
& \frac{\partial C_{i, Y}^{0}}{\partial t}=\delta_{Y, Y_{\text {nucl }}} g_{i+1, i} \gamma_{i+1}^{0} C_{i+1, Y}^{0}-g_{i, i-1} \gamma_{i}^{0} C_{i, Y}^{0} \\
& +\sum_{j=1}^{i} \sum_{k=1}^{i-1} f_{j, k, i} \beta_{j, k}^{0} N_{j}^{0} C_{k, Y}^{0}+\sum_{j=0}^{i} \sum_{k=0}^{i} f_{j, k, i} \alpha_{j, k}^{+,-}\left(N_{j}^{+} C_{k, Y}^{-}+C_{j, Y}^{+} N_{k}^{-}\right) \\
& -C_{i, Y}^{0}\left(\sum_{j=1}^{i_{\max }}\left(1-f_{i, j, i}\right) \beta_{i, j}^{0} N_{j}^{0}+\sum_{j=0}^{i_{\max }}\left(\beta_{j, i}^{+} N_{j}^{+}+\beta_{j, i}^{-} N_{j}^{-}\right)\right) \quad, \quad i \geq 2 \\
& \frac{\partial N_{1}^{0}}{\partial t}=P+g_{2,1} \gamma_{2}^{0} N_{2}^{0}+\sum_{j=2}^{i_{\max }} \gamma_{j}^{0} N_{j}^{0}+\sum_{j=1}^{i_{\max }}\left(\gamma_{j}^{+} N_{j}^{+}+\gamma_{j}^{-} N_{j}^{-}\right) \\
& -N_{1}^{0}\left(\sum_{j=1}^{i_{\max }}\left(1-f_{1, j, 1}\right) \beta_{1, j}^{0} N_{j}^{0}+\sum_{j=0}^{i_{\max }}\left(\beta_{j, 1}^{+} N_{j}^{+}+\beta_{j, 1}^{-} N_{j}^{-}\right)\right)
\end{aligned}
$$

In Eqs. (3)-(8), the superscripts “+”, “-”, “0” refer to positively charged, negatively charged, and neutral clusters, respectively. Subscripts $i, j, k$ are the bin indexes. $C_{i, Y}$ refers to the volume concentration $\left(\mathrm{cm}^{3} \mathrm{~cm}^{-3}\right)$ of component $\mathrm{Y}(\mathrm{Y}=\mathrm{A}, \mathrm{W}$, or $\mathrm{X})$ in the $i$ th bin, while $N_{i}$ is the number concentration $\left(\mathrm{cm}^{-3}\right)$ of cluster/particles in the bin $i$. In this study the nucleating species is A (i.e, $\mathrm{Y}_{\text {nucl }}=\mathrm{A}$ ). $\gamma$ is the cluster evaporation coefficient. $\beta_{i, j}^{+}, \beta_{i, j}^{-}, \beta_{i, j}^{0}$ are the coagulation kernels of the neutral clusters/particles in bin $j$ with positively charged, negatively charged, and neutral clusters/particles in bin $i$, respectively. When $j=1, \beta_{i, j}^{+}$, $\beta_{i, j}^{-}, \beta_{i, j}^{0}$ become the condensation coefficients of $\mathrm{H}_{2} \mathrm{SO}_{4}$ monomers. $\eta_{j, k}^{+}$and $\eta_{j, k}^{-}$are kernels of the coagulation between charged clusters/particles from bin $j$ with bin $k$ charged clusters/particles of the like sign. $\alpha_{i, j}^{+,-}$is the recombination coefficient of positively charged clusters/particles in bin $i$ with negatively charged clusters/particles in bin $j$, while $\alpha_{i, j}^{-,+}$is the recombination coefficient of bin $i$ 
negatively charged clusters/particles with positively charged clusters/particles in bin $j$. Due to the difference in the composition (and mass) of small positively and negatively charged clusters, $\alpha_{i, j}^{+,-}$is not equal to $\alpha_{i, j}^{-,+}$for small clusters $\left(i\right.$ or $\left.j<\mathrm{a}_{0}\right) . i_{\max }$ is the maximum number of bins in the model. $Q$ is the ionization rate and $P$ is the production rate of $\mathrm{H}_{2} \mathrm{SO}_{4}$ molecules. $T$ is the ambient temperature and $k$ is the Boltzmann's constant. $f_{j, k, i}$ is the volume fraction of intermediate particles (volume $=\mathrm{v}_{j}+\mathrm{v}_{k}$ ) partitioned into bin $i$, as defined in Jacobson et al. (1994). $g_{i+1, i}=\frac{v_{1}}{v_{i+1}-v_{i}}$ is the volume fraction of intermediate particles of volume $v_{i+1}-$ $v_{1, Y \text { nucl }}$ partitioned into bin $i$. $\delta_{Y, Y_{\text {nucl }}}$ accounts for the volume (or mass) of nucleating species (i.e., $\mathrm{H}_{2} \mathrm{SO}_{4}$ monomers) evaporated from the clusters, and is defined as

$\delta_{\mathrm{Y}, \mathrm{Y}_{\text {nucl }}}=\left\{\begin{array}{l}v_{i} / v_{i+1}, \quad \text { if } \mathrm{Y}=\mathrm{Y}_{\text {nucl }} \\ 1, \quad \text { if } \mathrm{Y} \neq \mathrm{Y}_{\text {nucl }}\end{array}\right.$

The change in the volume concentration of organic components ( $\mathrm{Y}=$ organics) in clusters/particles due to the condensation and evaporation of organic species is calculated using the following formulas

$$
\begin{aligned}
& \frac{\partial C_{i, \mathrm{org}}^{+,-, 0}}{\partial t}=\pi V_{\mathrm{org}} f_{\mathrm{corr}} N_{i}^{+,-, 0}\left(r_{i}^{+,-, 0}\right)^{2} \\
& v_{\text {org }}\left(P_{\text {org }}-P_{s, \text { org }} A_{\text {kelvin }}\right) \\
& f_{\text {corr }}=\frac{K n_{i}}{0.75+K n_{i}} \\
& A_{\text {kelvin }}=\exp \left(\frac{2 \sigma_{\mathrm{org}} v_{\mathrm{org}}}{k T r_{i}^{+,-, 0}}\right)
\end{aligned}
$$

where $V_{\text {org }}, v_{\text {org }}, P_{\text {org }}, P_{s, \text { org }}$, and $\sigma_{\text {org }}$ are the thermal speed, volume, vapor pressure, saturation vapor pressure, and surface tension of condensing organic molecules, respectively. $f_{\text {corr }}$ is the transitional correction factor (Seinfeld and Pandis, 1998). $A_{\text {kelvin }}$ describes the Kelvin effect. $r_{i}^{+,-, 0}$ is the wet radius of clusters/particles in bin $i$.

In order to simulate the cluster evolution and predict the nucleation rates in given conditions, $\beta, \gamma, \eta$, and $\alpha$ have to be defined. The methods for calculating $\beta, \eta$, and $\alpha$ have been discussed in our previous publications (Yu and Turco, 1998, 2001; Nadykto and Yu, 2003). Here we focus on the calculations of $\gamma$ because the explicit treatment of the evaporation of neutral and charged clusters is one of the key advancements of the current IMN model compared to the earlier version.

2.4 Evaporation coefficients of polar molecules from neutral and charged clusters

The evaporation rate coefficient of $\mathrm{H}_{2} \mathrm{SO}_{4}$ molecules from neutral clusters $\gamma_{i}^{0}$ can be calculated based on the saturation
$\mathrm{H}_{2} \mathrm{SO}_{4}$ vapor concentration over the surface of neutral cluster with radius $r_{i}^{0}$ (Yu, 2006b),

$\gamma_{i}^{0}=\beta_{1, i}^{0} \frac{\rho_{a, s}^{\text {total }}}{\rho_{a}^{\text {total }}} \exp \left(\frac{2 \sigma v_{a}}{k T r_{i}^{0}}\right)$

where $\rho_{a, s}^{\text {total }}$ is the total number concentration of $\mathrm{H}_{2} \mathrm{SO}_{4}$ molecules in the saturated vapor above a flat surface of a solution of the same composition as the cluster composition. $\rho_{a}^{\text {total }}\left(=N_{1}\right)$ is the total number concentration of sulfuric acid monomers (free + hydrated) in the nucleating system. $\sigma$ is the surface tension of the binary solution, and $v_{a}$ is the acid partial molecular volume. The exponential term takes into account the Kelvin effect.

The evaporation coefficients for $\mathrm{H}_{2} \mathrm{SO}_{4}$ molecules escaping from charged clusters $\gamma_{i}^{+}$and $\gamma_{i}^{-}$are calculated using the following equation

$\gamma_{i}^{+,-}=\left(\gamma_{i}^{0}\right)^{+,-} \times C E_{\text {Thomson }}^{+,-} \times C E_{\text {Dipole }}^{+,-}$

where $\left(\gamma_{i}^{0}\right)^{+,-}$is the evaporation coefficients for neutral clusters of the same size and composition as that of charged clusters. At $i \geq a_{0},\left(\gamma_{i}^{0}\right)^{+},\left(\gamma_{i}^{0}\right)^{-}$, and $\gamma_{i}^{0}$ are same, however, their values at $i<a_{0}$ are different due to the difference in the composition (see Eqs. 1-2). $C E_{\text {Thomson }}^{+,-}$describes the Thomson effect, while $C E_{\text {Dipole }}^{+,-}$takes into account the dipole-charge interaction effect (Yu, 2005a)

$$
\begin{aligned}
& C E_{\text {Thomson }}^{+,-}=\exp \left[-\frac{e^{2}}{8 \pi \varepsilon_{0} k T}\left(1-\frac{1}{\varepsilon_{l}}\right)\left(\frac{1}{r_{i-1}^{+,-}}-\frac{1}{r_{i}^{+,-}}\right)\right] \\
& C E_{\text {Dipole }}^{+,-}=\exp \left(-\frac{f^{+,-} \Delta \Phi_{\text {dipole }}^{+,-}}{k T}\right)
\end{aligned}
$$

$\Delta \Phi_{\text {dipole }}^{+,-}$is the extra energy needed to evaporate a polar molecules from charged clusters due to dipole-charge interaction with dipole orientation angle in the electrical field of a charged cluster expressed via the Langevin function (Yu, 2005a),

$\Delta \Phi_{\text {dipole }}^{+,-}=\frac{1}{2} \alpha E_{i-1}^{2}+\frac{3}{2} k T \ln \left(\frac{\exp \left(\frac{\mu_{0} E_{i-1}}{3 k T / 2}\right)-\exp \left(-\frac{\mu_{0} E_{i-1}}{3 k T / 2}\right)}{2 \frac{\mu_{0} E_{i-1}}{3 k T / 2}}\right)$

where $\mathrm{E}_{i-1}$ is the electric field strength at $r=r_{i-1}^{+,-}+r_{1}^{0}$ from the center of a core ion.

$f^{+,-}$in Eq. (16) is the parameter accounting for the observed sign preference and possible uncertainty associated with the usage of the Langevin function to approximate the dipole orientation angle. Although the Langevin function seems to be a good approximation (Yu, 2005a), the validity of this approach has to be assessed further. We think that the molecular bonding at the surface of the charged clusters may influence the dipole orientation angle $\theta$ at the moment when ligand breaks away from the surface, which may lead to a strong dependence of ion clustering thermodynamics on the properties of core ions (compositions, sign preference, etc.). In addition, the dependence of $\theta$ on $r$ (as a ligand moves 
away from the charged cluster) may differ from that given by the Langevin function.

$\mathrm{Yu}(2005 \mathrm{a})$ showed that the clustering enthalpies and entropies for protonated clusters $\left(\mathrm{H}^{+} \mathrm{L}_{n}\right.$, with $\mathrm{L}=\mathrm{H}_{2} \mathrm{O}, \mathrm{NH}_{3}$, $\mathrm{CH}_{3} \mathrm{OH}$, and $\mathrm{C}_{5} \mathrm{H}_{5} \mathrm{~N}$ ) predicted by MKT equation, which includes the dipole-charge interaction term (Eq. 16, $f^{+}=1$ ), are in a much better agreement with experimental results than those predicted by the classical Kelvin-Thomson (CKT) equation. Figure 3 presents the step-wise Gibbs free energy changes under the standard condition $\left(\Delta G_{n, n-1}^{0}\right)$ for the evaporation of $\mathrm{H}_{2} \mathrm{SO}_{4}$ from (a) $\mathrm{HSO}_{4}^{-}\left(\mathrm{H}_{2} \mathrm{SO}_{4}\right)_{\mathrm{n}}$ and (b) $\mathrm{HSO}_{4}^{-}\left(\mathrm{H}_{2} \mathrm{SO}_{4}\right)_{\mathrm{n}}\left(\mathrm{H}_{2} \mathrm{O}\right)_{\mathrm{m}}$. Symbols in the Fig. 3 refer to the experimental values. Dotted, dashed, solid, and dot-dashed lines in Fig. 3a are predictions based on traditional CKT equation (Holland and Castleman, 1982) and MKT equation (Yu, 2005a) with $f^{-}=1, f^{-}=r_{0} / r_{n}, f^{-}=\left(r_{0} / r_{n}\right)^{2}$, respectively. For the un-hydrated negative $\mathrm{H}_{2} \mathrm{SO}_{4}$ ions, measured $\Delta G_{n, n-1}^{0}$ at smaller $n$ are up to $\sim 10 \mathrm{kcal} / \mathrm{mol}$ larger than those predicted by CKT equation. $\Delta G_{n, n-1}^{0}$ predicted by MKT equation with $f^{-}=1$ are in very good agreement with observed values for small ion clusters $(n \leq \sim 4)$. For relatively large clusters $(n \geq \sim 4) \Delta G_{n, n-1}^{0}$ is few kcal/mole higher than the observed values. $f^{-}=r_{0} / r_{n}$ and $f^{-}=\left(r_{0} / r_{n}\right)^{2}$ reduce the values of $\Delta G_{n, n-1}^{0}$ for large clusters. We would like to emphasize that, due to the lack of data for large clusters $(n \geq \sim 4)$ and uncertainties in the experimental data, which are typically of a few $\mathrm{kcal} / \mathrm{mole}$ (Linstrom and Mallard, 2003), one can not determine precisely which $f$ gives the most realistic representation of dipole-charge interaction. In this study, we use $f^{-}=r_{0} / r_{n}$ as the base line case for the clustering of $\mathrm{H}_{2} \mathrm{SO}_{4}$ molecules with negative ions and $f^{-}=1$ and $f^{-}=\left(r_{0} / r_{n}\right)^{2}$ for the sensitivity study. For the hydrated negative $\mathrm{H}_{2} \mathrm{SO}_{4}$ ions, except for $n=1$, the differences between MKT predictions with $f^{-}=r_{0} / r_{n}$ and data are within $2 \mathrm{kcal} / \mathrm{mol}$ which is likely the uncertainty range of experimental data. For the number of water molecules considered here $(\mathrm{m}=0-3)$, the effect of hydration on $\Delta G_{n, n-1}^{0}$ is small except for $n=1$.

Observations indicate that nucleation rates of sulfuric acid on positive and negative ions are different (e.g., Laakso et al., 2004; Wilhelm et al., 2004; Vana et al., 2006). Although nucleation of $\mathrm{H}_{2} \mathrm{SO}_{4}-\mathrm{H}_{2} \mathrm{O}$ on negative ions is generally considered more favorable, the nucleation on positive ions remains important (Laakso et al., 2004; Wilhelm et al., 2004; Vana et al., 2006). Observations show that in some cases the nucleation on positive ions may prevail (Vana et al., 2006). Figure 4 gives the step-wise changes in the Gibbs free energy under the standard pressure $\left(\Delta G_{n, n-1}^{0}\right)$ associated with the evaporation of $\mathrm{H}_{2} \mathrm{SO}_{4}$ from $\mathrm{H}^{+}\left(\mathrm{H}_{2} \mathrm{O}\right)_{\mathrm{w}}\left(\mathrm{H}_{2} \mathrm{SO}_{4}\right)_{\mathrm{n}}$ (a) at $w=1$, (b) $w=2$, and (c) $w=3$. Symbols refer to the data from Froyd (2002) and Froyd and Lovejoy (2003a). Solid and dotted lines are results obtained using the MKT equation with $f^{+}=-r_{0} / r_{n}$ and predictions of CKT equation, respectively. In contrast to the evaporation of $\mathrm{H}_{2} \mathrm{SO}_{4}$ from negative ions
(Fig. 3), CKT equation over-predicts the Gibbs free energy change by up to $5-10 \mathrm{kcal} / \mathrm{mole}$ for $\mathrm{H}^{+}\left(\mathrm{H}_{2} \mathrm{O}\right)_{\mathrm{w}} \mathrm{H}_{2} \mathrm{SO}_{4}-->$ $\mathrm{H}^{+}\left(\mathrm{H}_{2} \mathrm{O}\right)_{\mathrm{w}}+\mathrm{H}_{2} \mathrm{SO}_{4}(w=1,2,3)$. It is nice to see that the MKT equation with $f^{+}=-r_{0} / r_{n}$ gives an excellent agreement with the available experimental data. In this study, we use $f^{+}=-r_{0} / r_{n}$ for the clustering of $\mathrm{H}_{2} \mathrm{SO}_{4}$ molecules with positive ions. It important to note that further research (experimental ion-clustering investigations and/or quantum mechanism studies) is needed in order to evaluate the current parameterizations thoroughly.

As it has been shown in Figs. 3-4, our treatment of the dipole-charge interaction term and sign preference is consistent with the available thermodynamic data on ion clustering within the uncertainty range. Figure 5 shows the values of (a) $\gamma_{i}^{+},\left(\gamma_{i}^{0}\right)^{+}$, and $\gamma_{i}^{0}$, (b) $\gamma_{i}^{-},\left(\gamma_{i}^{0}\right)^{-}$, and, $\gamma_{i}^{0}$. The growth rates of neutral and charged clusters/particles $\left(\beta_{i, 1}^{0} N_{1}, \beta_{i, 1}^{+} N_{1}\right.$, and, $\left.\beta_{i, 1}^{-} N_{1}\right)$ with sulfuric gas concentration $\left(\left[\mathrm{H}_{2} \mathrm{SO}_{4}\right]\right.$ or $\left.N_{1}\right)$ of $10^{7} \mathrm{~cm}^{-3}$ are also given in Fig. 5. The evaporation rates are independent of $N_{1}$, while the growth rates are proportional to $N_{1}$. The cluster composition, $T$, RH have significant effect on $\gamma_{i}$, while their effect on cluster growth rate is small. $\left(\gamma_{i}^{0}\right)^{+}$is much smaller than $\gamma_{i}^{0}$, however, $\left(\gamma_{i}^{0}\right)^{-}$is much larger than $\gamma_{i}^{0}$ for small clusters $(i<\sim 6)$ due to the difference in the composition (see Fig. 2). The total charge effect (Thomson effect + dipole-charge interaction effect) significantly reduces the evaporation coefficients of small negative ion clusters and it moderately reduces the evaporation coefficients of small positively charged cluster ions. Different values of $f^{-}$assigned to negative ions in order to estimate possible uncertainties related to the dipolecharge interaction lead to an uncertainty in $\gamma_{i}^{-}$(a factor of 24 from the baseline case) (see Fig. 5b). Growth rates of small charged clusters are $\sim 2-8$ higher than those of neutral clusters. The intersection points of $\beta_{i, 1} N_{1}$ and $\gamma_{i}$ curves show the location of critical clusters. It should be noted that our current model uses the parameterized composition as average cluster composition with respect to water and doesn't consider the effect of hydration distribution on the evaporation flux. Same approximation has been applied in our kinetic model of binary $\mathrm{H}_{2} \mathrm{SO}_{4}-\mathrm{H}_{2} \mathrm{O}$ homogeneous nucleation ( $\mathrm{Yu}$, 2006b). The effect of hydration distribution on evaporation should be evaluated in the future when more data on hydration and $\mathrm{H}_{2} \mathrm{SO}_{4}$ clustering thermodynamics become available. The major uncertainty of the current model is likely to be dominated by the uncertainty in $\mathrm{H}_{2} \mathrm{SO}_{4}$ clustering thermodynamics (as well as hydration thermodynamics). More accurate data extending to large clusters are needed to reduce the uncertainty.

Although the critical size for charged clusters is smaller than that for neutral clusters, a charged cluster that reaches its critical size should not be considered as "nucleated" until it reaches the size corresponding to the critical size of a neutral cluster because the charged cluster neutralized before it reaches the size of the neutral critical cluster may evaporate. 

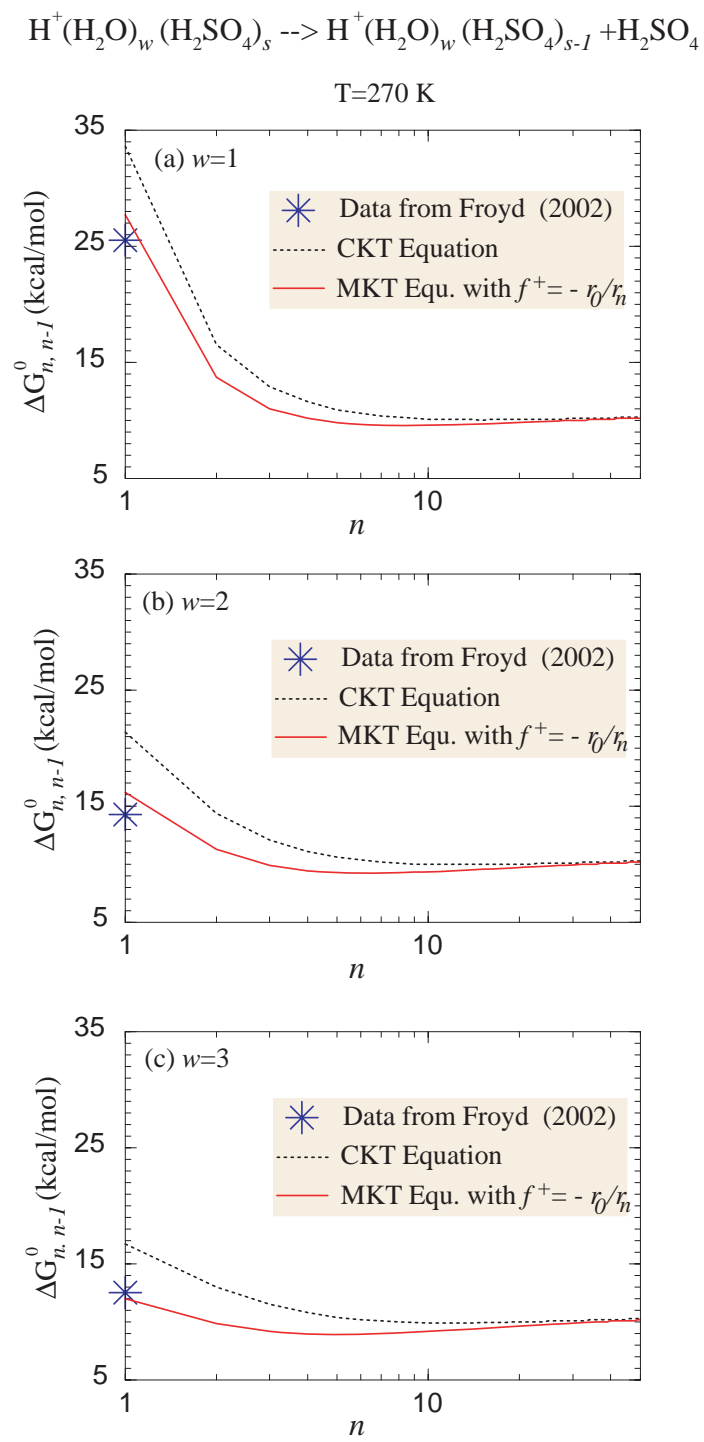

Fig. 4. Step-wise Gibbs free energy changes under the standard pressure $\left(\Delta G_{n, n-1}^{0}\right)$ for the evaporation of $\mathrm{H}_{2} \mathrm{SO}_{4}$ from $\mathrm{H}^{+}\left(\mathrm{H}_{2} \mathrm{O}\right)_{\mathrm{w}}\left(\mathrm{H}_{2} \mathrm{SO}_{4}\right)_{\mathrm{n}}$ with (a) $w=1$, (b) $w=2$, and (c) $w=3$. Symbols refer to the data from Froyd (2002) and Froyd and Lovejoy (2003a). Solid and dotted lines are the predictions based on MKT equation with $f^{+}=-r_{0} / r_{n}$ and CKT equation, respectively.

Under the conditions given in Fig. 5, there is a nucleation barrier for both positive and negative ions. The barrier peak for positive ions is located around $i=7$, while that for negative ions is located near $i=\sim 3-4$. The nucleation barriers for both positive and negative ions vary with $T, \mathrm{RH}$, and $N_{1}$.

\section{Simulations and results}

\subsection{Evolution of clusters and nucleation rates}

The evolution of cluster/particle size distributions can be obtained by solving the dynamic Eqs. (3)-(8). Many practical applications require information on the steady state nucle- ation rates. In the simulations presented in this section, we assume a constant $N_{1}, T, \mathrm{RH}, Q$, and surface area of preexisting particles $(S)$, and solve Eqs. (3)-(8) to obtain the steady state cluster distribution and nucleation rate. At $t=0$, only neutral monomers exist $\left(N_{1}^{0}=N_{1}\right)$, and concentrations of all the other clusters (including initial core ions) are set to be zero. The pre-existing particles with fixed surface area serve as a sink for all clusters. The condensation of organics is not included in this part.

Figure 6 shows the evolution of cluster size distributions $\left(\mathrm{dN} / \mathrm{d} \log \mathrm{D}_{p}\right)$ for two cases with different $N_{1}$ : (a1,2,3) $N_{1}=5 \times 10^{6} \mathrm{~cm}^{-3}$; (b-1,2,3) $N_{1}=1.5 \times 10^{7} \mathrm{~cm}^{-3}$. In both cases, $T=285 \mathrm{~K}, \mathrm{RH}=75 \%, Q=5$ ion-pairs $\mathrm{cm}^{-3} \mathrm{~s}^{-1}$, and $S=50 \mu \mathrm{m}^{2} \mathrm{~cm}^{-3}$. The inserted figures give the size 

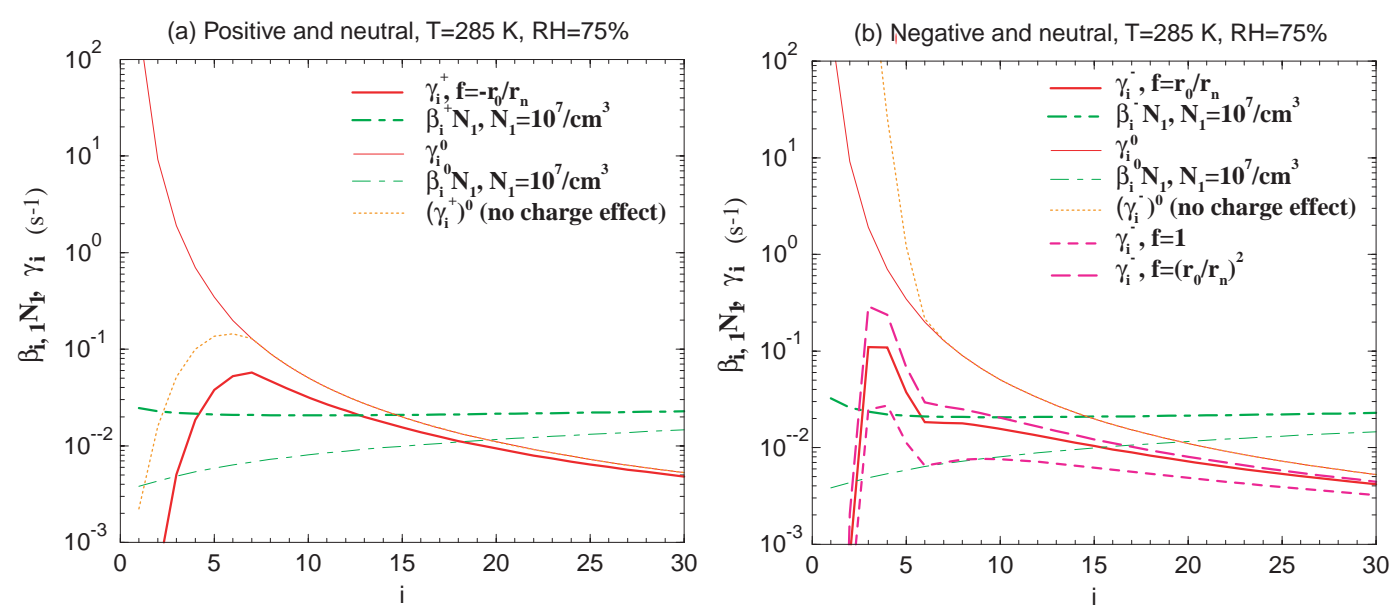

Fig. 5. The growth rates and evaporation coefficients of charged clusters at $T=285 \mathrm{~K}, \mathrm{RH}=75 \%$, and $N_{1}=10^{7} / \mathrm{cm}^{3}:(\mathbf{a})$ positive $\left(\beta_{i, 1}^{+} N_{1}, \gamma_{i}^{+}\right.$ with $\left.f^{+}=-r_{0} / r_{n}\right)$ and (b) negative $\left(\beta_{i, 1}^{-} N_{1}, \gamma_{i}^{-}\right.$with $\left.f^{-}=1, f^{-}=r_{0} / r_{n}, f^{-}=\left(r_{0} / r_{n}\right)^{2}\right)$. The evaporation coefficients and growth rates of neutral clusters $\left(\gamma_{i}^{0}, \beta_{i, 1}^{0} N_{1}\right)$ are given in both panels for the comparison. Note that the compositions of small charged/neutral clusters (containing less than $7 \mathrm{H}_{2} \mathrm{SO}_{4}$ molecules) are different. The dotted lines are the evaporation coefficients of neutral clusters having the same sizes and compositions as the charged ones.

distributions at four selected times. The diameter of neutral critical clusters is $2.18 \mathrm{~nm}$ in the case (a) and $1.85 \mathrm{~nm}$ in the case (b). The evolution of positively charged, negatively charged, and neutral clusters can be clearly seen from Fig. 6 . Spectra of clusters smaller than $\sim 1.5 \mathrm{~nm}$ reach the steady state within 5 to $10 \mathrm{~min}$. Due to the existence of growth barriers for both positive and negative ions (see Fig. 5), the concentration of small positive ions peaks around $1 \mathrm{~nm}$, while that of the negative clusters peaks around $0.7 \mathrm{~nm}$. This behavior of small positive and negative cluster ions is consistent with recent observations (Laakso et al., 2004; Vana et al., 2006). Only few clusters grow beyond $1.5 \mathrm{~nm}$ in case (a) due to the lower $\mathrm{H}_{2} \mathrm{SO}_{4}$ concentration. A significant number of negative ions grow beyond $1.5 \mathrm{~nm}$ in case (b), however most of these ions were neutralized before approaching $3 \mathrm{~nm}$ in size. There exists a clearly visible mode of neutral particles centering around $2-3 \mathrm{~nm}$ that resulted from the neutralization of charged clusters/particles. Nucleation of negative ions was found to be favorable in both cases.

The nucleation rates in the second-generation IMN model (denoted as $J_{\text {IMN }}$ ) are calculated based on the net fluxes of particles across the critical size of neutral clusters $\left(i=i^{*}\right)$,

$$
\begin{aligned}
J_{\mathrm{IMN}} & =\beta_{i, 1}^{0} N_{1}^{0} N_{i *}^{0}-\gamma_{i}^{0} N_{i *+1}^{0}+\beta_{i, 1}^{+} N_{1}^{0} N_{i *}^{+} \\
& -\gamma_{i}^{+} N_{i *+1}^{+}+\beta_{i, 1}^{-} N_{1}^{0} N_{i *}^{-}-\gamma_{i}^{-} N_{i *+1}^{-}
\end{aligned}
$$

Figure 7 shows $J_{\text {IMN }}$ as a function of time corresponding to the cases shown in Fig. 6. For each case, three curves corresponding to three different $f^{-}$(see Fig. 3) are given to show the sensitivity of nucleation rates to the thermochemistry of the ion clustering. Our results show that $J_{\text {IMN }}$ initially increases with time, however it reaches a steady-state value after $\sim 45 \mathrm{~min}$ for case (a) and $\sim 15 \mathrm{~min}$ for case (b). The steady state values of $J_{\text {IMN }}$ are $1.5 \times 10^{-7}, 4.5 \times 10^{-6}$, and $3.4 \times 10^{-3} \mathrm{~cm}^{-3} \mathrm{~s}^{-1}$ for case (a) and $0.17,0.54,1.5 \mathrm{~cm}^{-3} \mathrm{~s}^{-1}$ for case (b) with $f^{-}=\left(r_{0} / r_{n}\right)^{2}, f^{-}=r_{0} / r_{n}, f^{-}=1$, respectively. In the given conditions, the uncertainty in $f^{-}$leads to approximately one order of magnitude difference in $J_{\text {IMN }}$ in the case (b) and about four orders of magnitude difference in $J_{\text {IMN }}$ in the case (a). It appears that the uncertainty in $J_{\text {IMN }}$ associated with $f^{-}$is relatively small, when nucleation rate is large $\left(\sim 1 \mathrm{~cm}^{-3} \mathrm{~s}^{-1}\right)$ and becomes larger when $J_{\mathrm{IMN}}$ is lower. In the simulations presented below $f^{-}=r_{0} / r_{n}$ has been used.

The steady state values of $J_{\mathrm{IMN}}$ depend on $T, \mathrm{RH}, N_{1}, Q$, and $S$. Figure 8 presents $J_{\mathrm{IMN}}$ as a function of time under nine different combinations of $T$, RH, $N_{1}, Q$, and $S$. Here we focus on the conditions, which are typical for lower troposphere (boundary layer). $N_{1}$ and $T$ are the two most important parameters controlling the particle formation. $\mathrm{RH}, Q$, and $S$ affect the nucleation rates at a lesser degree. For high $N_{1}$ (up to $10^{8} \mathrm{~cm}^{-3}$ in polluted areas such as in the downwind of power plants), IMN can lead to a significant particle nucleation even if the ambient temperature $T$ is $\sim 290 \mathrm{~K}$. When $N_{1}$ is $\sim 1.5 \times 10^{7} \mathrm{~cm}^{-3}, T=275 \mathrm{~K}$ can lead to high nucleation rates at $\mathrm{RH}>\sim 75 \%$. When $N_{1}$ is $\sim 5 \times 10^{6} \mathrm{~cm}^{-3}$, $T<275 \mathrm{~K}$ and RH above $60 \%$ lead to a noticeable nucleation $\left(>0.1 \mathrm{~cm}^{-3} \mathrm{~s}^{-1}\right)$.

Based on the simulations performed using the second generation IMN we found that ion-mediated nucleation can lead to a significant new particle formation in the lower atmosphere (including boundary layer) under favorable conditions. Our results are different from the predictions of the ion nucleation model of Lovejoy et al. (2004), which indicates that the nucleation of $\mathrm{H}_{2} \mathrm{SO}_{4}$ (and $\mathrm{H}_{2} \mathrm{O}$ ) on negative ions 
Case (a):T285RH75A0.5E7S50Q5
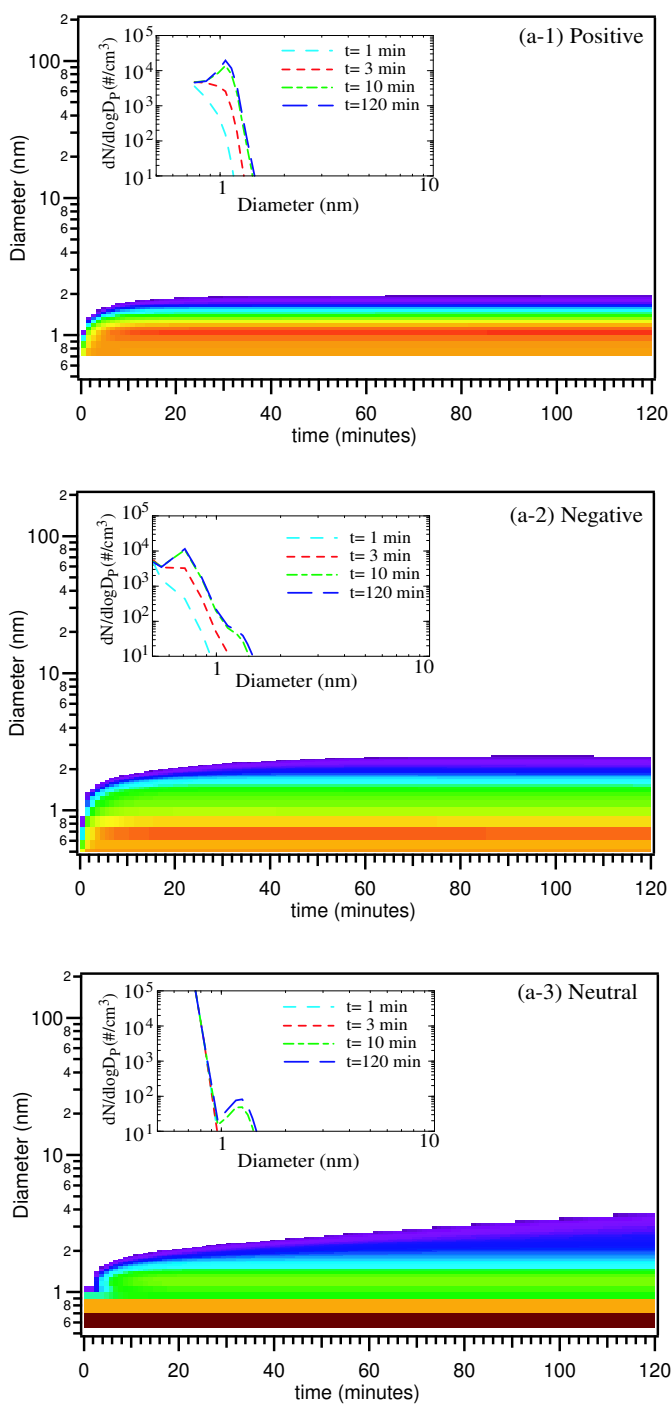

Case (b): T285RH75A1.5E7S50Q5
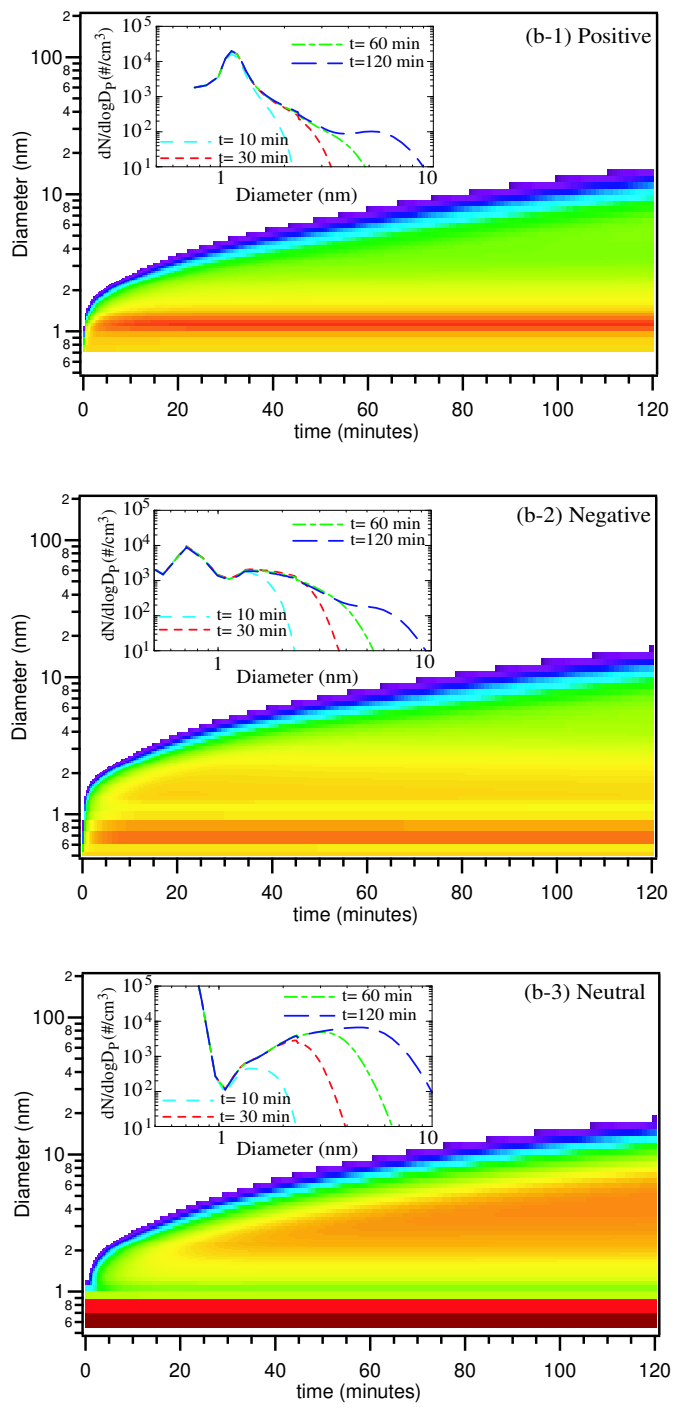

$10^{6}$

$\mathrm{dN} / \mathrm{dlogDp}\left(\# / \mathrm{cm}^{3}\right)$

Fig. 6. Evolution of the size distribution $\left(\mathrm{d} N / \mathrm{d} \log D_{p}\right)$ of positive, negative, and neutral clusters for two cases with different $N_{1}$ : (a-1,2,3) $N_{1}=5 \times 10^{6} \mathrm{~cm}^{-3} ;(\mathrm{b}-1,2,3) N_{1}=1.5 \times \times 10^{7} \mathrm{~cm}^{-3}$. For both cases, $T=285 \mathrm{~K}, \mathrm{RH}=75 \%, Q=5$ ion-pairs cm $\mathrm{c}^{-3} \mathrm{~s}^{-1}$, and $S=50 \mu \mathrm{m}^{2} \mathrm{~cm}^{-3}$. The insert in each panel gives the size distributions at four selected times.

does not generally explain the observed nucleation events in the boundary layer (Modgil et al., 2005). The possible reasons for this deviation are discussed below:

1. The thermodynamics of ion clusters may be different. The ion-clustering thermodynamic data used in the model by Lovejoy et al. (2004) were obtained via a combination of measurements of small ion clusters, ab initio calculations, thermodynamic cycle, and approximations (extrapolation of data for small clusters to large clusters by adding empirical terms to Thomson equation that decayed exponentially with cluster size, etc.). In our model, the thermodynamical properties of ion clusters were calculated using modified Kelvin-Thomson equation, which explicitly takes into account dipole-charge interaction and is consistent with ion clustering experiments for a variety of systems (see Figs. 3-4 in the present paper and $\mathrm{Yu}, 2005 \mathrm{a})$. 


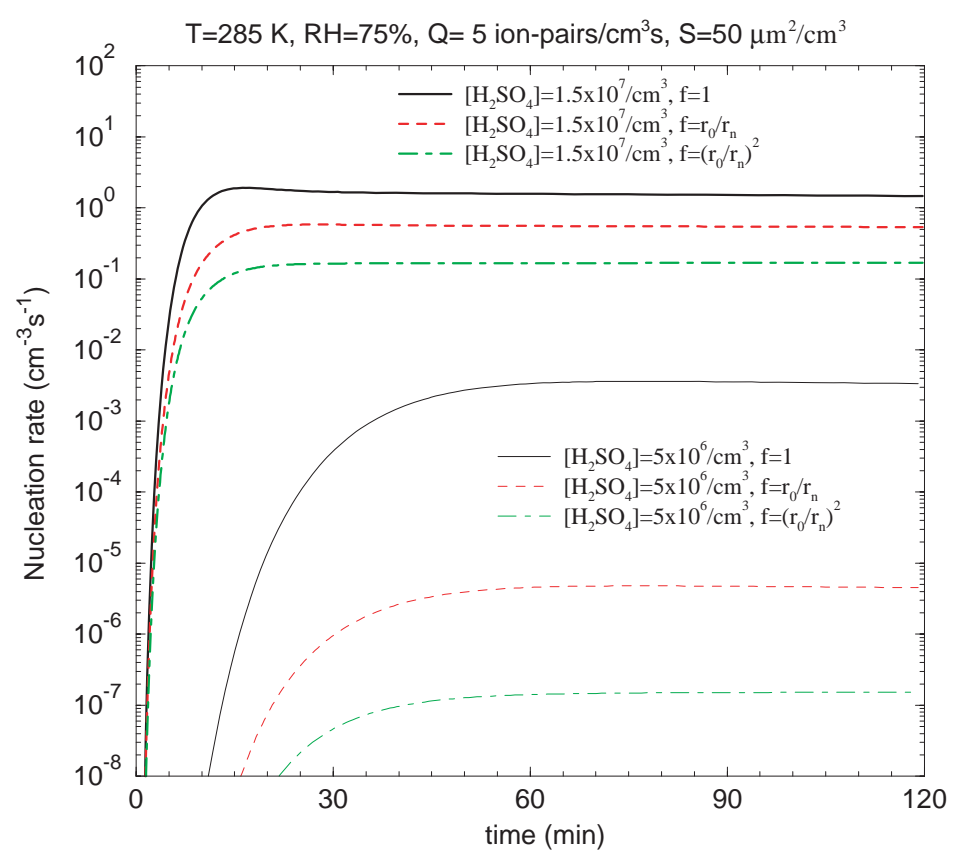

Fig. 7. Ion-mediated nucleation rates as a function of time corresponding to the cases shown in Fig. 6. For each case, three curves corresponding to three different $f^{-}$are given to show the sensitivity of nucleation rates to ion-clustering thermodynamic parameterizations.

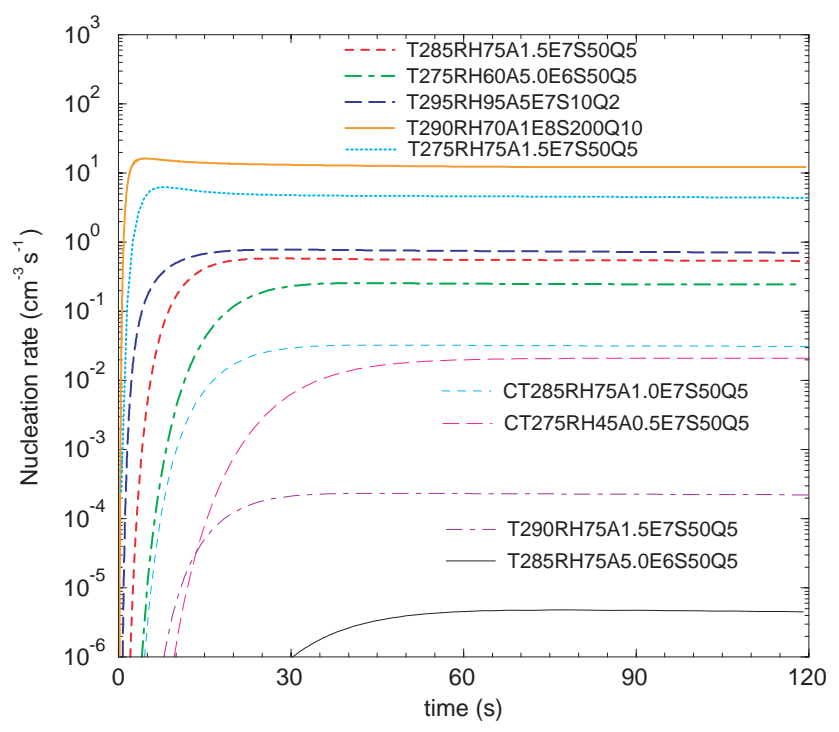

Fig. 8. Ion-mediated nucleation rates as a function of time under nine different combinations of $T, \mathrm{RH}, N_{1}$, Q, and $S$. Read T285RH75A1.5E7S50Q5 as the case with $T$ of $285 \mathrm{~K}, \mathrm{RH}$ of $75 \%,\left[\mathrm{H}_{2} \mathrm{SO}_{4}\right]$ (or $N_{1}$ ) of $1.5 \times 10^{7} \mathrm{~cm}^{-3}$, surface area of $50 \mu \mathrm{m}^{2} / \mathrm{cm}^{3}$, and ionization rate of 5 ion-pairs $\mathrm{cm}^{-3} \mathrm{~s}^{-1}$.

2. There exists some difference in the treatment of positive ions/clusters. In the model of Lovejoy et al. (2004) positive ions are treated as a single species (initial ions containing no $\mathrm{H}_{2} \mathrm{SO}_{4}$ ) and they are not allowed to grow. In our model, clustering of positive ions and interaction of positive ions of different sizes with negative and neutral clusters was explicitly resolved. As it has been shown in
Fig. 6, which demonstrates the agreement between our model results and recent field measurements (Laakso et al., 2004; Vana et al., 2006), the concentration of small positive ions peaks around $1 \mathrm{~nm}$ that corresponds to a cluster containing $\sim 4 \mathrm{H}_{2} \mathrm{SO}_{4}$ molecules. Assumption that all positive ions are single species containing no $\mathrm{H}_{2} \mathrm{SO}_{4}$ may influence the model predictions given by 
Lovejoy et al. (2004) in a number of ways. Here we would like to consider two main aspects. First, this assumption may cause the underestimation of the lifetime of negative ions due to recombination because the recombination coefficient between two ions decreases significantly as the sizes of the recombining ions increase. Secondly, this assumption leads to the underestimation of the sizes of neutrals resulted from the recombination of charged clusters. Both aspects lead to an obvious under-prediction of the nucleation rates.

3. The thermodynamic data used for $\mathrm{H}_{2} \mathrm{SO}_{4}-\mathrm{H}_{2} \mathrm{O}$ binary system may be different. Lovejoy et al. (2004) used the vapor pressures calculated with the On-Line Aerosol Inorganics Model (Carslaw et al., 1995) and the parameterizations of the density from Perry and Chilton (1973) and surface tension from Sabinina and Terpugow (1935). In order to make the nucleation rates produced by their model consistent with the experimental results of Ball et al. (1999), Lovejoy et al. (2004) added empirical terms, $4 \exp (-\mathrm{a} / 5)$ and $5 \exp (-\mathrm{w} / 5)$ (units of $\mathrm{kcal} / \mathrm{mol}$ ), to their liquid droplet Gibbs free energies associated with the addition of $\mathrm{H}_{2} \mathrm{SO}_{4}$ and $\mathrm{H}_{2} \mathrm{O}$, respectively, to $\left(\mathrm{H}_{2} \mathrm{SO}_{4}\right)_{a}(\mathrm{H} 2 \mathrm{O})_{w}$ clusters. These terms systematically decrease the bonding energies of $\mathrm{H}_{2} \mathrm{SO}_{4}$ and $\mathrm{H}_{2} \mathrm{O}$ and reduce the nucleation rates (Lovejoy et al., 2004). While the empirical term may improve the agreement of model predictions with experimental results under the laboratory conditions, there is no physics behind the terms that will ensure their validity at other temperature. In our model, the saturation vapor pressure over the binary system is calculated using the recent parameterization of Taleb et al. (1996) with the pure acid saturation vapor pressure given by Noppel et al. (2002), and the bulk cluster density and surface tension are calculated using the most recently updated parameterizations of Vehkamaki et al. (2002). No adjustments were made to these parameterizations. Our kinetic $\mathrm{H}_{2} \mathrm{SO}_{4}$ $\mathrm{H}_{2} \mathrm{O}$ binary homogeneous nucleation (BHN) model predicts BHN rates within with the uncertainty range of the laboratory measurements (Yu, 2005b, 2006b). The difference in the thermodynamics of neutral clusters may have significant impacts on the ion nucleation rates because the thermodynamics of ionic clusters depends on that of neutral ones (see for example Eq. 14) and the stability of neutral clusters formed via the recombination is critically important.

\subsection{Nucleation coupled with growth}

In the atmosphere, the nucleation and growth processes are coupled. The freshly nucleated particles are typically $\sim 2 \mathrm{~nm}$ or smaller in size; however it has been frequently observed that these particles can grow to the sizes of cloud condensation nuclei within a day (Kulmala, 2003; Stanier et al., 2004; Zhang et al., 2004a; Wehner et al., 2005). It has also been found that organics appear to dominate the growth of nucleated particles in many observed nucleation and growth events (Kulmala et al., 2004a, b).

In Sect. 3.1, $\left[\mathrm{H}_{2} \mathrm{SO}_{4}\right]$ was fixed and organics condensation was not considered. In this section, we study the evolution of neutral and charged particles with a time-dependent concentration of $\mathrm{H}_{2} \mathrm{SO}_{4}$ and organics. We focus on the coupling between the nucleation and growth processes in the presence and in the absence of organics. To take into account the diurnal variations of precursor gas concentrations in the atmosphere, we parameterized $\left[\mathrm{H}_{2} \mathrm{SO}_{4}\right]$ and [organics] as

$\left[\mathrm{H}_{2} \mathrm{SO}_{4}=\left[\mathrm{H}_{2} \mathrm{SO}_{4 \max } \sin ^{2} \pi(t-4) / 12,16 \geq t \geq 4\right.\right.$
organics $=$ organics $\max _{\max } \sin ^{0.5} \pi(t-6) / 12,18 \geq t \geq 6$

where $t$ is the local time (hour). $\quad\left[\mathrm{H}_{2} \mathrm{SO}_{4}\right]_{\max }$ and [organics] $]_{\max }$ are the peak concentrations of $\left[\mathrm{H}_{2} \mathrm{SO}_{4}\right]$ and [organics], respectively. The minimum concentrations of $\mathrm{H}_{2} \mathrm{SO}_{4}$ and organics are assumed to be $5 \times 10^{5} \mathrm{~cm}^{-3}$ and $5 \times 10^{6} \mathrm{~cm}^{-3}$, respectively. The time-dependent concentrations of $\mathrm{H}_{2} \mathrm{SO}_{4}$ and organics with $\left[\mathrm{H}_{2} \mathrm{SO}_{4}\right]_{\max }=1.5 \times 10^{7} \mathrm{~cm}^{-3}$ and [organics $]_{\max }=5 \times 10^{7} \mathrm{~cm}^{-3}$, which are used to run the model, are shown in Fig. 9. It is important to note that $\left[\mathrm{H}_{2} \mathrm{SO}_{4}\right]$ and [organics] and their variations may be different in different locations/days and Fig. 8 represents one of the possible scenarios.

The evolutions of the size distribution of positively charged, negatively charged, neutral, and total clusters/particles with $\left[\mathrm{H}_{2} \mathrm{SO}_{4}\right]$ variations as described in Fig. 9 are shown in Fig. 10: without $(\mathrm{a}-1,2,3,4)$ and with (b$1,2,3,4)$ organics condensation. To focus our investigation on the effect of the precursor gas concentration, we assume a constant $T$ of $280 \mathrm{~K}$ and RH of $50 \%$ during the period of the simulation. The organic species is assumed to have a saturation pressure of $2.5 \times 10^{6} \mathrm{~cm}^{-3}$, molecular weight of $200 \mathrm{~g} / \mathrm{mol}$, density of $1.2 \mathrm{~g} \mathrm{~cm}^{-3}$, and surface tension of $30 \mathrm{erg} \mathrm{cm}^{-2}$. The surface area of pre-existing particles is $\sim 50 \mu \mathrm{m}^{2} \mathrm{~cm}^{-3}$. The evolution of small clusters that lead, as $\left[\mathrm{H}_{2} \mathrm{SO}_{4}\right]$ increases, to the nucleation and growth of nanoparticles is demonstrated in Fig. 10. Under the condition studied here the concentration of small positive ions peaks around $1 \mathrm{~nm}$, while that of negative ions peak around $0.7 \mathrm{~nm}$ when $\left[\mathrm{H}_{2} \mathrm{SO}_{4}\right]>\sim 2 \times 10^{6} \mathrm{~cm}^{-3}$. When $\left[\mathrm{H}_{2} \mathrm{SO}_{4}\right]$ is very low $\left(<2 \times 10^{6} \mathrm{~cm}^{-3}\right.$ in this case $)$, initial core ions are most abundant. In the atmosphere, other species (such as $\mathrm{HNO}_{3}, \mathrm{NH}_{3}$, organic compounds, etc) may also be involved in the formation of small ions, especially when $\left[\mathrm{H}_{2} \mathrm{SO}_{4}\right]$ is low. A mode of negative ions between $1-3 \mathrm{~nm}$ is clearly visible during the nucleation period, while there is no such a mode in the size spectrum of the positive ions. The nucleation on negative ions is obviously more favorable in such conditions. There exists a pool of neutral clusters/particles smaller than $\sim 3 \mathrm{~nm}$, which resulted from the recombination of oppositely charged cluster ions. Without the condensation 


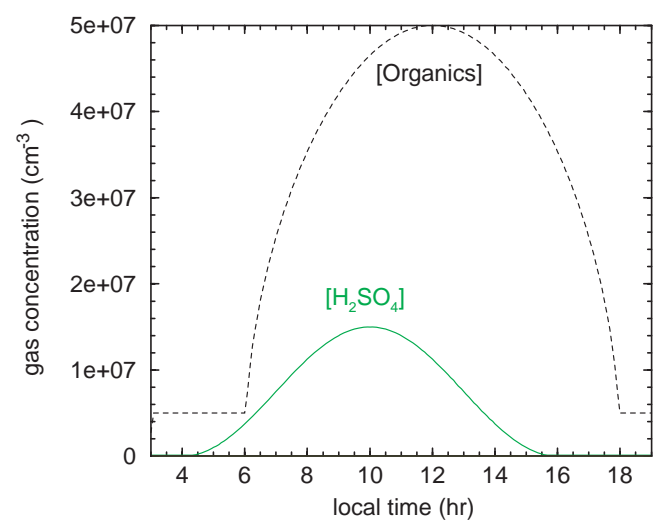

Fig. 9. Time-dependent concentrations of $\mathrm{H}_{2} \mathrm{SO}_{4}$ and organics assumed in our simulations with $\left[\mathrm{H}_{2} \mathrm{SO}_{4}\right]_{\mathrm{max}}=1.5 \times 10^{7} \mathrm{~cm}-3$ and [organics] $]_{\max }=5 \times 10^{7} \mathrm{~cm}^{-3}$. The minimum concentrations of $\mathrm{H}_{2} \mathrm{SO}_{4}$ and organics are assumed to be $5 \times 10^{5} \mathrm{~cm}^{-3}$ and $5 \times 10^{6} \mathrm{~cm}^{-3}$, respectively.

of organics, the specified $\left[\mathrm{H}_{2} \mathrm{SO}_{4}\right]$ result in growth of the freshly nucleated particles to $\sim 10 \mathrm{~nm}$. However, in the presence of organics (see Fig. 9) the nucleated particles grow to $30-80 \mathrm{~nm}$. Due to the Kelvin effect, organics can condense only if particles are larger than $\sim 3 \mathrm{~nm}$ in size. A small mode of particles between 2 and $3 \mathrm{~nm}$ in Fig. 10b-3 is a result of the evaporation of neutral clusters smaller than $2 \mathrm{~nm}$ (critical size of neutral clusters around $2 \mathrm{~nm}$ ) and the activation of clusters larger than $3 \mathrm{~nm}$ by organics condensation. The activation diameter for organics depends on the super-saturation ratio and Kelvin effect and it may be as small as $\sim 2 \mathrm{~nm}$ under some conditions (Kerminen et al., 2004). The obvious gap in the number size distributions of positive and negative ions/particles shown in Fig. 10b-1, 2 is associated with the activation of particles/cluster by organics and neutralization of charged nucleated particles.

In our model, the compositions of clusters /particles have been resolved. Fig. 11 shows the evolution of particle mass size distributions for the case corresponding to Fig. 10b: (a) $\mathrm{H}_{2} \mathrm{SO}_{4}$, (b) Organics. The dry volume of initial pre-existing particles is assumed to be composed of $50 \% \mathrm{H}_{2} \mathrm{SO}_{4}$ and $50 \%$ organics. It may be seen clearly from Fig. 11 that organics contribute to the mass of particles larger than $3 \mathrm{~nm}$. Moreover, the composition of nucleated particles larger than $\sim 10 \mathrm{~nm}$ is dominated by the organics.

3.3 Size-dependent charging state of nanoparticles during nucleation/growth events

The aerosol particles in the atmosphere generally have an equilibrium charge distribution due to the diffusion of small ions to the particles. The equilibrium charged fraction $(\mathrm{CF}$, concentration of positively or negatively charged particles divided by total particle concentration in the size range) of particles decreases as particle size decreases. The nucleation and growth events may disturb the equilibrium charge distribution of nanoparticles because a characteristic time needed to reach the equilibrium may be longer than the cluster/particle growth time. CFs of both positive and negative can be readily calculated in our new IMN model, which simulates the size distributions of positive, negative, and neutral clusters/particles explicitly.

Figure 12 shows the evolution of CFs for the case corresponding to Fig. 10b (with organics): (a) positive, (b) negative. As can be seen from Fig. 12, there exists a minimum $\mathrm{CF}$ of $\sim 2-3 \%$ during the nucleation period. The diameter $\left(d_{m}\right)$ of minimum CF is $\sim 2.5-7 \mathrm{~nm}$ for positive and $\sim 4-8 \mathrm{~nm}$ for negative ions, respectively. The minimum is formed due to the neutralization of nanoparticles nucleated on ions and an increase in the charging probability with increasing particle size. Another important feature is the charge asymmetry for particles smaller than $\sim 4 \mathrm{~nm}$. Particles from the size range between 2 and $4 \mathrm{~nm}$ are significantly negatively overcharged (i.e., the charged fraction is much higher than that in the equilibrium state) while they are only slightly positively overcharged. Most of the particles between 1.5-2 nm are negatively charged, while most of the particles between $1-1.5 \mathrm{~nm}$ are positively charged. Under the specific conditions simulated here, the nucleation on negative ions is preferred. The existence of a minimum CF $\sim 4-6 \mathrm{~nm}$ (with CF of $\sim 2-3 \%$ ) and charge asymmetry for particles smaller than $\sim 4 \mathrm{~nm}$ in size are consistent with the measurements (Vana et al., 2006).

Our simulations indicate that while ions play an important role in the new particle formation, the nucleated particles loss their memory of ions (i.e., carrying a charge) after they grow to a certain size $\left(d_{m}\right)$ due to the recombination. The values of $d_{m}$ depend on the concentrations of precursor gases, concentrations and sizes of small ions, surface area of pre-existing particles, and ambient conditions $(T, \mathrm{RH})$. Systematic investigation of $\mathrm{CF}$ distributions under a variety of atmospheric conditions will be carried out in the future. 

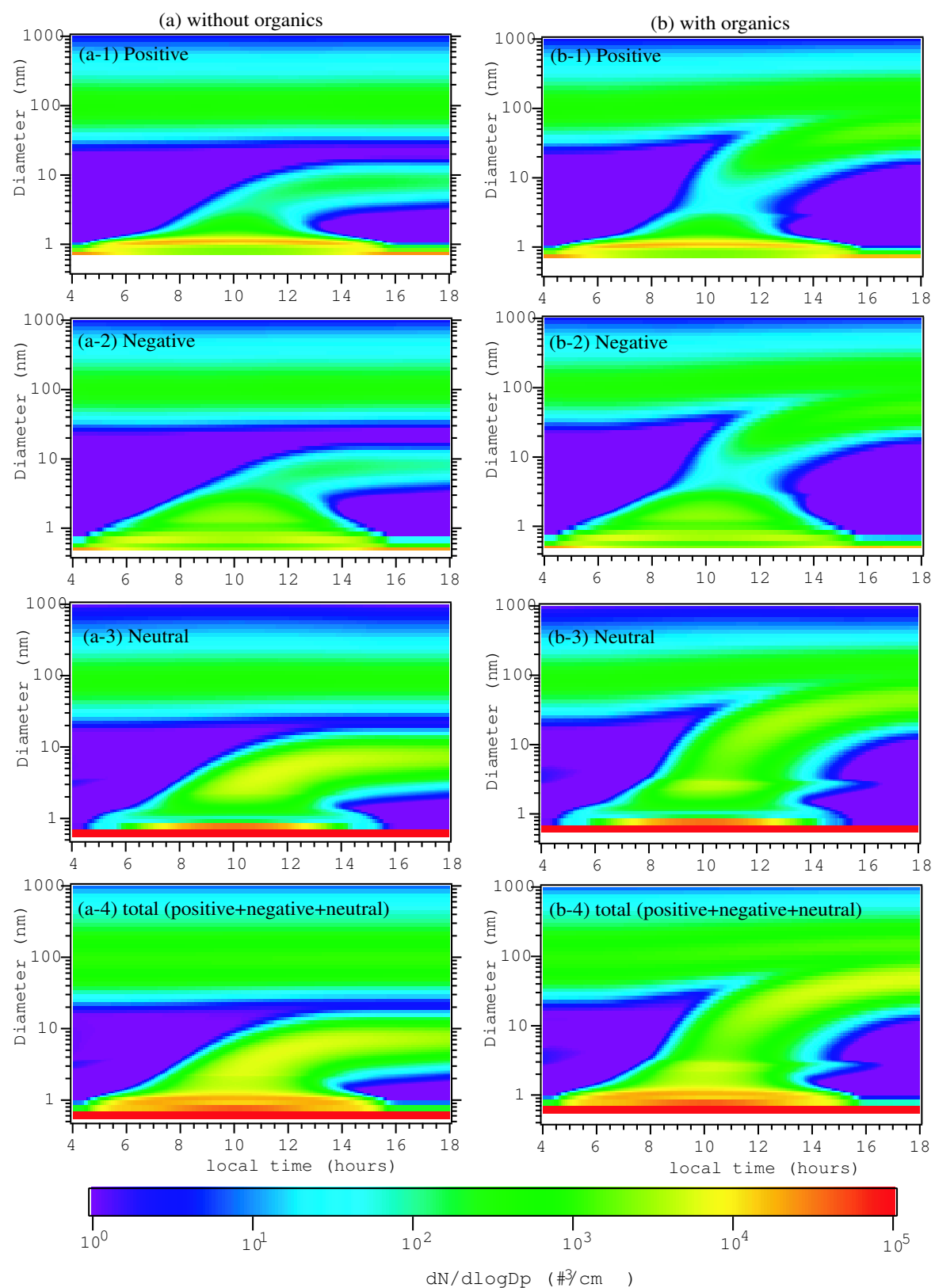

Fig. 10. The size distribution evolutions of positively charged, negatively charged, neutral, and total clusters/particles with $\left[\mathrm{H}_{2} \mathrm{SO}_{4}\right]$ variations as described in Fig. 9: (a) without organics condensation; (b) with organics condensation.

In recent years, advanced instruments to measure charged sub-nanometer and fine nanometer particles in the atmospheric air have been developed by Tammet (e.g., 2006) and they have been employed in a number of the field studies (e.g, Laakso et al., 2004; Vana et al., 2006; Iida et al., 2005). Simultaneous measurements of the size distribution of charged and total particles during the nucleation events give the charging fraction of freshly nucleated particles, and such measurements provide very useful information about the nucleation mechanisms in terms of the involvement of ions in the atmospheric nucleation. The observed (both negative and positive) overcharge of particles smaller than $\sim 4$ $5 \mathrm{~nm}$ clearly indicates that ions can lead to the nucleation in boundary layer atmosphere, that agrees well with our model prediction. Detailed comparisons of the observed evolutions of the ion mobility and particle size spectrums during nucleation events (Laakso et al., 2004; Vana et al., 2006; Iida et al., 2005 ) with the predictions of our model shall provide useful insights about the mechanisms of new particle formation. 

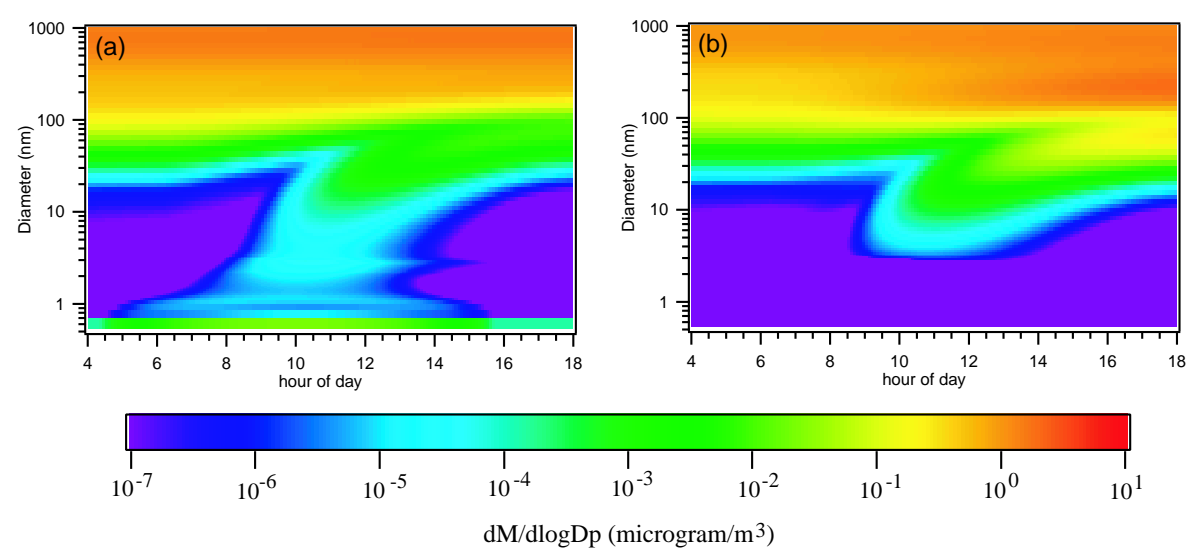

Fig. 11. Evolution of particle mass size distributions for the case corresponding to Fig. 10b: (a) $\mathrm{H}_{2} \mathrm{SO}_{4}$, (b) Organics.
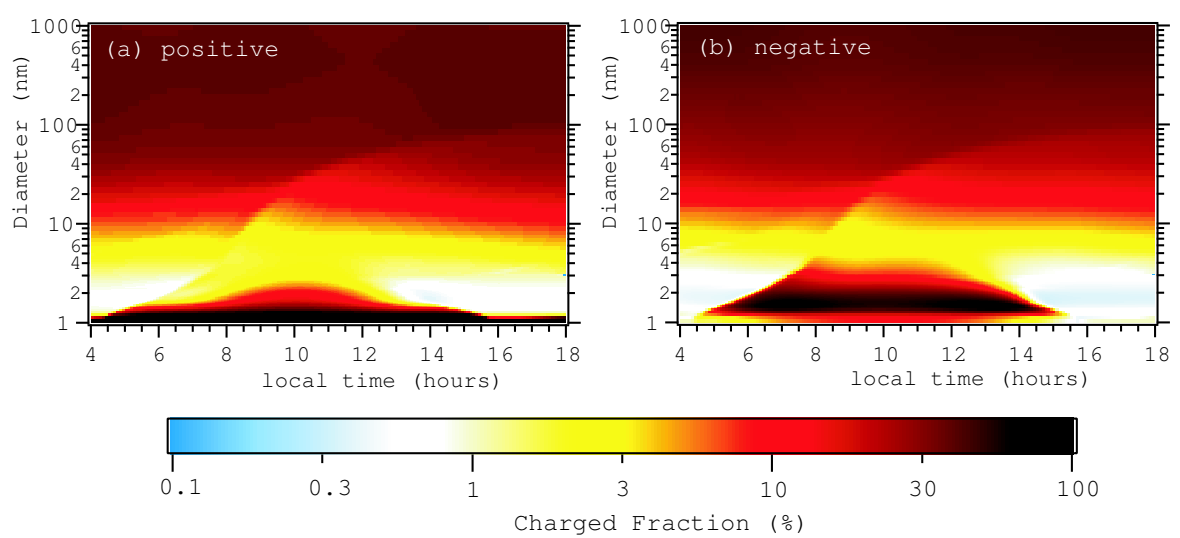

Fig. 12. Evolution of the fractions of the charged particles for the case corresponding to Fig. 10b (with organics): (a) positive, (b) negative.

\section{Summary and discussion}

A clear and insightful understanding of the secondary aerosol formation in the atmosphere remains to be achieved. In recent years there is an increasing interest in the nucleation involving ions. In this paper we present a new second generation ion-mediated nucleation model that treats the evaporation of neutral/charged clusters explicitly and solves the evolutions of the sizes and compositions of positively charged, negatively charged, and neutral clusters/particles ranging from molecules to large particles of few micrometers in size. Schemes to calculate the evaporation coefficients of small neutral and charged clusters were shown to be consistent with experimental data. The new model explicitly accounts for the difference in the composition and thermodynamics of small positive and negative ions. The second generation IMN model enables us to simulate in detail the evolution of small charged/neutral and the coupling of the nucleation with growth. The condensation of low volatile organics and sulfuric acid on the nucleated particles were simulated and composition of the grown particles was obtained.
The fraction of positively and negatively charged particles as a function of particle sizes can be calculated using our new model.

The specific features of the spectra of small positive and negative ions were successfully predicted by the new IMN model. The peak concentration of positive ions at $\sim 1 \mathrm{~nm}$ and peak concentration of negative ions at $\sim 0.7 \mathrm{~nm}$, as well as the sign preference, were predicted by our new model in agreement with the observations. Our results suggest that IMN can lead to a significant new particle formation in the lower atmosphere (including boundary layer) under favorable conditions. Our results are different from predictions of Lovejoy et al. (2004) which suggest that that the nucleation of $\mathrm{H}_{2} \mathrm{SO}_{4}$ (and $\mathrm{H}_{2} \mathrm{O}$ ) on negative ions does not generally explain the observed nucleation events in the boundary layer. The possible reasons for the difference include the different thermodynamic data used for $\mathrm{H}_{2} \mathrm{SO}_{4}-\mathrm{H}_{2} \mathrm{O}$ binary system, the difference in the treatment of positive ions/clusters, and different thermochemistry of ion clustering.

Our simulations of charged particle fraction as a function of the particle size during nucleation and growth events 
indicate the existence of a minimum charging fraction at particle size $\sim 2.5-7 \mathrm{~nm}$ for positive and $\sim 4-8 \mathrm{~nm}$ for negative ionic clusters. The value of the minimum $\mathrm{CF}$ is $\sim 2-3 \%$. The minimum is due to the neutralization of nanoparticles nucleated on ions and the increase of the charging probability with the particle size. The charge asymmetry for particles smaller than $\sim 4 \mathrm{~nm}$, which can be clearly seen from our simulations, suggests a negative sign preference in the ion mediated nucleation under the conditions studied here. These findings are consistent with the recent measurements of nanoparticle CFs (Vana et al., 2006).

The presented second generation ion-mediated nucleation model is a powerful tool to study ion-mediated nucleation under different atmospheric conditions and analyze the simultaneous measurements of ion-mobility spectra and particle size distributions, which become available only recently (e.g., Laakso et al., 2004; Vana et al., 2006; Iida et al., 2005). The model is subject to some uncertainties associated with the thermodynamics of small neutral and charged clusters. Laboratory investigations or/and quantum mechanical studies of the thermodynamics of pre-nucleation clusters would help to reduce these uncertainties. In the atmosphere, species other than $\mathrm{H}_{2} \mathrm{SO}_{4}$ and $\mathrm{H}_{2} \mathrm{O}$ (such as $\mathrm{NH}_{3}, \mathrm{HNO}_{3}$, and organics) may affect the properties of small clusters and the nucleation rates. Such effects remain to be investigated further.

Acknowledgements. The author is grateful to A. Nadykto for useful discussions. This work was supported by the NSF under grant ATM 0104966 and 0618124 by the NOAA/DOC under grant NA05OAR4310103.

Edited by: M. Kulmala

\section{References}

Arnold, F. and Qiu, S.: Upper stratosphere negative ion composition measurements and infrared trace gas abundances, Planet. Space Sci., 32, 169-177, 1984.

Arnold, F., Viggiano, A. A., and Schlager, H.: Implications for Trace Gases and Aerosols of Large Negative Ions Clusters in the Stratosphere, Nature, 297, 371, 1982.

Ball, S. M., Hanson, D. R., Eisele, F. L., and McMurry, P. H.: Laboratory studies of particle nucleation: Initial results for $\mathrm{H}_{2} \mathrm{SO}_{4}$, $\mathrm{H}_{2} \mathrm{O}$, and $\mathrm{NH}_{3}$ vapors, J. Geophys. Res., 104, 23 709-23 718, doi:10.1029/1999JD900411, 1999.

Carslaw, K. S., Harrison, R. G., and Kirkby, J.: Cosmic rays, clouds and climate, Science, 298, 1732-1737, 2002.

Carslaw, K. S., Clegg, S. L., and Brimblecombe P.: A thermodynamic model of the system $\mathrm{HCl}-\mathrm{HNO}_{3}-\mathrm{H}_{2} \mathrm{SO}_{4}-\mathrm{H}_{2} \mathrm{O}$, including solubilities of $\mathrm{HBr}$ from $<200$ to $328 \mathrm{~K}$, J. Phys. Chem., 99, $11557-11574,1995$.

Charlson, R. J., Schwartz, S. E., Hales, J. M., Cess, R. D., Coakley, J. A. Jr., Hansen, J. E., and Hofmann, D. J.: Climate forcing by anthropogenic aerosols, Science, 255, 423-430, 1992.
Clarke, A. D., Davis, D, Kapustin, V. N., et al.: Particle nucleation in the tropical boundary layer and its coupling to marine sulfur sources, Science, 282, 89-92, 1998.

Coffman, D. J. and Hegg, D. A.: A preliminary study of the effect of ammonia on particle nucleation in the marine boundary layer, J. Geophys. Res., 100, 7147-7160, 1995.

Eichkorn, S., Wilhelm, S., Aufmhoff, H., Wohlfrom, K. H., and Arnold, F.: Cosmic ray-induced aerosol-formation: First observational evidence from aircraft-based ion mass spectrometer measurements in the upper troposphere, Geophys. Res. Lett., 29(14), 1698, doi:10.1029/2002GL015044, 2002.

Eisele, F. L. and Tanner, D. J.: Identification of ions in continental air, J. Geophys. Res., 95(D12), 20 539-20 550, 1990.

Fiedler, V., Dal Maso, M., Boy, M., et al.: The contribution of sulphuric acid to atmospheric particle formation and growth: a comparison between boundary layers in Northern and Central Europe, Atmos. Chem. Phys., 5, 1773-1785, 2005, http://www.atmos-chem-phys.net/5/1773/2005/.

Froyd, K. D. and Lovejoy, E. R.: Experimental thermodynamics of cluster ions composed of $\mathrm{H}_{2} \mathrm{SO}_{4}$ and $\mathrm{H}_{2} \mathrm{O}$. 1. Positive ions, J. Phys. Chem. A, 107, 9800-9811, 2003a.

Froyd, K. D. and Lovejoy, E. R.: Experimental thermodynamics of cluster ions composed of $\mathrm{H}_{2} \mathrm{SO}_{4}$ and $\mathrm{H}_{2} \mathrm{O}$. 2. Measurements and ab initio structures of negative ions, J. Phys. Chem. A, 107, 9812-9824, 2003b.

Froyd, K. D.: Ion induced nucleation in the atmosphere: Studies of $\mathrm{NH}_{3}, \mathrm{H}_{2} \mathrm{SO}_{4}$, and $\mathrm{H}_{2} \mathrm{O}$ cluster ions, Ph.D. thesis, Univ. of Colo., Boulder, 2002.

Hamill, P., Turco, R. P., Kiang, C. S., Toon, O. B., and Whitten, R. C.: An analysis of various nucleation mechanisms for sulfate particles in the stratosphere, J. Aerosol Sci., 13, 561-585, 1982.

Harrison, R. G. and Carslaw, K. S.: Ion-aerosol-cloud processes in the lower atmosphere, Rev. Geophys., 41(3), 1012, doi:10.1029/2002RG000114, 2003.

Holland, P. M. and Castleman, A. W., Jr.: Thomson equation revisited in light of ion-clustering experiments, J. Phys. Chem., 86, 4181-4188, 1982.

Hõrrak, U., Salm, J., and Tammet H.: Burst of intermediate ions in atmospheric air, J. Geophys. Res., 103, 13 909-13 915, 1998.

Iida, K., Stolzenburg, M., McMurry, P., Smith, J., Dunn, M., and Eisele, F.: Atmospheric field study of ion-induced nucleation, abstract of American Association for Aerosol Research 24rd Annual Conference, Austin, Texas, 17-21 October, 2005.

Jacobson, M. Z. and Turco, R. P.: Simulating condensational growth, evaporation and coagulation of aerosols using a combined moving and stationary size grid, Aerosol Sci. Tech., 22, 73-92, 1995.

Jacobson, M., Turco, R., Jensen, E., and Toon O.: Modeling coagulation among particles of different composition and size, Atmos. Environ., 28, 1327-1338, 1994.

Kerminen, V., Anttila, T., Lehtinen, K., and Kulmala M.: Parameterization for atmospheric new-particle formation: application to a system involving sulfuric acid and condensable water-soluble organic vapors, Aerosol Sci. Technol., 38, 1001-1008, 2004.

Korhonen, P., Kulmala, M., Laaksonen, A., Viisanen, Y., McGraw, R., and Seinfeld, J. H.: Ternary nucleation of $\mathrm{H}_{2} \mathrm{SO}_{4}, \mathrm{NH}_{3}$, and $\mathrm{H}_{2} \mathrm{O}$ in the atmosphere, J. Geophys. Res., 104, 26349-26353, 1999.

Kulmala, M., Lehtinen, K. E. J., and Laaksonen A.: Cluster activa- 
tion theory as an explanation of the linear dependence between formation rate of $3 \mathrm{~nm}$ particles and sulphuric acid concentration, Atmos. Chem. Phys., 6, 787-793, 2006, http://www.atmos-chem-phys.net/6/787/2006/.

Kulmala, M., Vehkamäki, H., Petäjä, T., Dal Maso, M., Lauri, A., Kerminen, V.-M., Birmili, W., and McMurry, P.: Formation and growth rates of ultrafine atmospheric particles: A review of observations, J. Aerosol Sci., 35, 143-176, 2004a.

Kulmala, M. , Laakso, L., Lehtinen, K. E. J., Riipinen, I., Dal Maso, M., Anttila, T., Kerminen, V.-M., Hõrrak, U., Vana, M., and Tammet, H.: Initial steps of aerosol growth, Atmos. Chem. Phys., 4, 2553-2560, 2004b.

Kulmala, M.: How particles nucleate and grow, Science, 302, 10001001, 2003.

Laakso, L., Anttila, T., Lehtinen, K. E. J., Aalto, P. P., Kulmala, M., Hõrrak, U., Paatero, J., Hanke, M., and Arnold, F.: Kinetic nucleation and ions in boreal forest particle formation events, Atmos. Chem. Phys., 4, 2353-2366, 2004, http://www.atmos-chem-phys.net/4/2353/2004/.

Laakso, L., Mäkelä, J. M., Pirjola, L., and Kulmala, M.: Model studies of ion-induced nucleation in the atmosphere, J. Geophys. Res., 107, 4427, doi:10.1029/2002JD002140, 2003.

Laaksonen, A., Hamed, A., Joutsensaari, J., Hiltunen, L., Cavalli, F., Junkermann, W., Asmi, A., Fuzzi, S., and Facchini, M. C.: Cloud condensation nucleus production from nucleation events at a highly polluted region, Geophys. Res. Lett., 32, L06812, doi:10.1029/2004GL022092, 2005.

Lee, S.-H., Reeves, J. M., Wilson, J. C., Hunton, D. E., Viggiano, A. A., Miller, T. M., Ballenthin, J. O., and Lait, L. R.: New particle formation by ion-induced nucleation in the upper troposphere and lower stratosphere, Science, 26, 1886-1889, 2003.

Linstrom, P. J. and Mallard, W. G. (Eds.): NIST Chemistry WebBook, NIST Standard Reference Database Number 69, March 2003, National Institute of Standards and Technology, Gaithersburg MD, 20899 (http://webbook.nist.gov), 2003.

Lovejoy, E. R., Curtius, J., and Froyd, K. D.: Atmospheric ioninduced nucleation of sulfuric acid and water, J. Geophys. Res., 109, D08204, doi:10.1029/2003JD004460, 2004.

Mäkelä, J. M., Salm, J., Smirnov, V. V., Koponen, I., Paatero, J., and Pronin, A. A.: Measurements of the mobility distribution of air ions as a source of information for the study of aerosol generation, Proceedings of the $12^{\text {th }}$ International Conference on Atmospheric Electricity, 2003.

Modgil, M. S., Kumar, S., Tripathi, S. N., and Lovejoy, E. R.: A parameterization of ion-induced nucleation of sulphuric acid and water for atmospheric conditions, J. Geophys. Res., 110, D19205, doi:10.1029/2004JD005475, 2005.

Nadykto, A. and Yu, F.: Uptake of neutral polar vapour molecules by charged particles: Enhancement due to dipole-charge interaction, J. Geophy. Res., 108(D23), 4717, doi:10.1029/2003JD003664, 2003.

Nadykto, A. and Yu, F.: Dipole moment of condensing monomers: A new parameter controlling the ion-induced nucleation, Phys. Rev. Lett., 93, 016101, doi:10.1103/PhysRevLett.93.016101, 2004.

Nadykto, A., Mäkelä, J., Yu, F., Kulmala, M. and Laaksonen, A.: Comparison of the experimental mobility equivalent diameter for small cluster ions with theoretical particle diameter corrected by effect of vapour polarity, Chem. Phys. Lett., 382/1-2, 6-11, 2003.
Nadykto, A. B., Al Natsheh, A., Yu, F., Mikkelsen, K. V., and Ruuskanen, J.: Quantum nature of the sign preference in the ion-induced nucleation, Phys. Rev. Lett., 96, 125701, doi:10.1103/PhysRevLett.96.125701, 2006.

Napari, I., Noppel, M., Vehkamäki, H., and Kulmala, M.: Parametrization of ternary nucleation rates for $\mathrm{H}_{2} \mathrm{SO}_{4}$ $\mathrm{NH}_{3}-\mathrm{H}_{2} \mathrm{O}$ vapors, J. Geophys. Res., 107(D19), 4381, doi:10.1029/2002JD002132, 2002.

Noppel, M., Vehkamäki, H., and Kulmala, M.: An improved model for hydrate formation in sulfuric-acid water nucleation, J. Chem. Phys, 116, 218-228, 2002.

O’Dowd, C. D., Jimenez, J. L., Bahreini, R., et al.: Marine aerosol formation from biogenic iodine emissions, Nature, 417, 632636, 2002.

Penner, J. E., Andreae, M., Annegarn, H., et al.: Aerosols, their direct and indirect effects, in Climate Change 2001: The Scientific Basis, Working Group I contribution to the IPCC Third Assessment Report: Summary for policymakers, 289-348, 2001.

Perry, R. H. and Chilton, C. H.: Chemical Engineers' Handbook, 5th ed., McGraw-Hill, New York., 1973.

Sabinina, A. L. and Terpugow, L.: Die oberflächenspannung de systems schwefelsäure-wasser, Z. Phys. Chem. A, 173, 237-241, 1935.

Seinfeld J. H. and Pandis S. N.: Atmospheric Chemistry and Physics - from Air Pollution to Climate Change, John Wiley and Sons, New York, NY, 1998.

Sorokin, A., Arnold, F., and Wiedner, D.: Formation and growth of sulfuric acid-water cluster ions: Experiments, modelling, and implications for ion-induced aerosol formation, Atmos. Environ., 40, 2030-2045, 2006.

Stanier, C., Khlystov, A., and Pandis, S. N.: Nucleation events during the Pittsburgh Air Quality Study: Description and relation to key meteorological, gas phase, and aerosol parameters, Aerosol Sci. Technol., 38, suppl. 1, 253-264, 2004.

Stolzenburg, M. R., McMurry, P. H., Sakurai, H., Smith, J. N., Mauldin III, R. L., Eisele, F. L., and Clement, C. F.: Growth rates of freshly nucleated atmospheric particles in Atlanta, J. Geophys. Res., 110, D22S05, doi:10.1029/2005JD005935, 2005.

Taleb, D.-E., Ponche, J.-L., and Mirabel, P.: Vapor pressures in the ternary system water-nitric acid-sulfuric acid at low temperature: A reexamination, J. Geophys. Res., 101, 25 967-25 977, 1996.

Tamm, E., Hõrrak, U., Mirme, A., and Vana, M.: On the charge distribution on atmospheric nanoparticles, J. Aerosol Sci., 32, S347-S348, 2001.

Tammet, H.: Continuous scanning of the mobility and size distribution of charged clusters and nanometer particles in atmospheric air and the Balanced Scanning Mobility Analyzer BSMA, Atmos. Res., in press, 2006.

Toon, O. B., Turco, R. P., Westphal, D., Malone, R., and Liu, M. S.: A multidimensional model for aerosols: Description of computational analogs, J. Atmos. Sci., 45, 2123-2143, 1988.

Turco, R. P., Hamill, P., Toon, O. B., Whitten, R. C., and Kiang, C. S.: A one-dimensional model describing aerosol formation and evolution in the stratosphere, Part I, Physical processes and mathematical analogs, J. Atmos. Sci., 36, 699-717, 1979.

Twomey, S.: The influence of pollution on the shortwave albedo of clouds, J. Atmos. Sci., 34, 1149-1152, 1977.

Vana, M., Tamm, E., Hõrrak, U., Mirme, A., Tammet, H., Laakso, L., Aalto, P. P., and Kulmala, M.: Charging state of nanoparticles 
during the nucleation burst events, Atmos. Res., in press, 2006.

Vehkamäki H., Kulmala, M., Napari, I., Lehtinen, K. E. J., Timmreck, C., Noppel, M., and Laaksonen, A.: An improved parameterization for sulfuric acid-water nucleation rates for tropospheric and stratospheric conditions, J. Geophys. Res., 107 (D22), 4622, doi:10.1029/2002JD002184, 2002.

Weber, R. J., Marti, J. J., McMurray, P. H., Eisele, F. L., Tanner, D. J. and Jefferson, A.: Measured atmospheric new particle formation rates: Implications for nucleation mechanisms, Chem. Eng. Comm., 151, 53-64, 1996.

Wehner, B., Petäjä, T., Boy, M., Engler, C., Birmili, W., Tuch, T., Wiedensohler, A., and Kulmala, M.: The contribution of sulfuric acid and non-volatile compounds on the growth of freshly formed atmospheric aerosols, Geophys. Res. Lett., 32, L17810, doi:10.1029/2005GL023827, 2005.

Wilhelm, S., Eichkorn, S., Wiedner, D., Pirjola, L., and Arnold, F.: Ion-induced aerosol formation: new insights from laboratory measurements of mixed cluster ions, $\mathrm{HSO}_{4}^{-}\left(\mathrm{H}_{2} \mathrm{SO}_{4}\right)_{a}\left(\mathrm{H}_{2} \mathrm{O}\right)_{w}$ and $\mathrm{H}^{+}\left(\mathrm{H}_{2} \mathrm{SO}_{4}\right)_{a}\left(\mathrm{H}_{2} \mathrm{O}\right)_{w}$, Atmos. Environ., 38, 1735-1744, 2004.

Yu, F.: Modified Kelvin-Thomson equation considering iondipole interaction: Comparison with observed ion-clustering enthalpies and entropies, J. Chem. Phys., 122, 084503, doi:10.1063/1.1845395, 2005a.

Yu, F.: Quasi-unary homogeneous nucleation of $\mathrm{H}_{2} \mathrm{SO}_{4}-\mathrm{H}_{2} \mathrm{O}, \mathrm{J}$. Chem. Phys., 122, 074501, doi:10.1063/1.1845395, 2005 b.

Yu, F.: Effect of ammonia on new particle formation: A kinetic $\mathrm{H}_{2} \mathrm{SO}_{4}-\mathrm{H}_{2} \mathrm{O}-\mathrm{NH}_{3}$ nucleation model constrained by laboratory measurements, J. Geophys. Res., 111, D01204, doi:10.1029/2005JD005968, 2006a.

Yu, F.: Binary H2SO4-H2O homogeneous nucleation rates based on a kinetic quasi-unary model: Look-up tables, J. Geophy. Res., 111, D04201, doi:10.1029/2005JD006358, 2006 b.

Yu, F.: Altitude variations of cosmic ray induced production of aerosols: Implications for global cloudiness and climate, J. Geophys. Res., 107(A17), 1118, doi:10.1029/2001JA000248, 2002.

Yu, F. and Turco, R. P.: Ultrafine aerosol formation via ionmediated nucleation, Geophys. Res. Lett., 27, 883-886, 2000.

Yu, F. and Turco, R. P.: From molecular clusters to nanoparticles: The role of ambient ionization in tropospheric aerosol formation, J. Geophys. Res., 106, 4797-4814, 2001.

Yu, F. and Turco, R. P.: The formation and evolution of aerosols in stratospheric aircraft plumes: Numerical simulations and comparisons with observations, J. Geophy. Res., 103, 25 915-25 934, 1998.

Yu, F. and Turco, R. P.: The role of ions in the formation and evolution of particles in aircraft plumes, Geophys. Res. Lett., 24, 1927-1930, 1997.

Zhang, Q., Stanier, C., Canagaratna, M., Jayne, J., Worsnop, D., Pandis, S. and Jimenez, J.: Insights into Nucleation Burst and Particle Growth in Pittsburgh Based on Aerosol Mass Spectrometry, Environ. Sci. Technol., 38, 4797-4809, 2004a.

Zhang, R., Suh, I., Zhao, J., Zhang, D., Fortner, E. C., Tie, X., Molina, L. T., and Molina, M. J.:Atmospheric new particle formation enhanced by organic acids, Science, 304, 1487-1490, 2004b. 